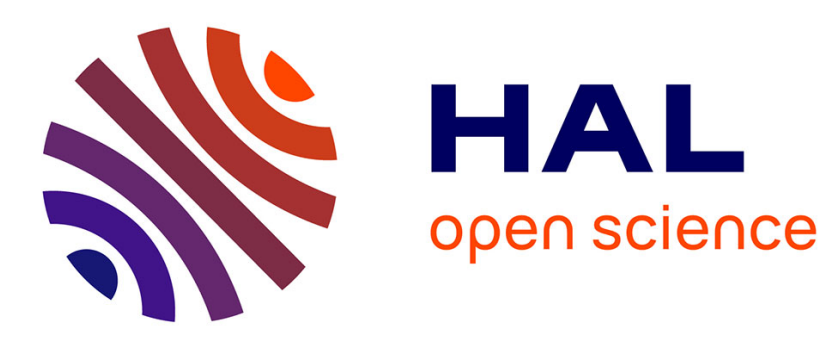

\title{
Recent advances in the synthesis of natural multifunctionalized decalins
}

S. Dhambri, S. Mohammad, O. Nguyen van Buu, G. Galvani, Y. Meyer, M.-I. Lannou, G. Sorin, J. Ardisson

\section{- To cite this version:}

S. Dhambri, S. Mohammad, O. Nguyen van Buu, G. Galvani, Y. Meyer, et al.. Recent advances in the synthesis of natural multifunctionalized decalins. Natural Product Reports, 2015, 32 (6), pp.841-864. 10.1039/c4np00142g . hal-02370535

\section{HAL Id: hal-02370535 \\ https://hal.science/hal-02370535}

Submitted on 14 Oct 2021

HAL is a multi-disciplinary open access archive for the deposit and dissemination of scientific research documents, whether they are published or not. The documents may come from teaching and research institutions in France or abroad, or from public or private research centers.
L'archive ouverte pluridisciplinaire HAL, est destinée au dépôt et à la diffusion de documents scientifiques de niveau recherche, publiés ou non, émanant des établissements d'enseignement et de recherche français ou étrangers, des laboratoires publics ou privés. 


\title{
Recent advances in the synthesis of natural multifunctionalized decalins
}

\author{
S. Dhambri, S. Mohammad, O. Nguyen Van Buu, G. Galvani, Y. Meyer, M.-I. Lannou, * \\ G. Sorin* and J. Ardisson*
}

Covering: 2007 to August 2014

This review highlights recent innovative synthetic strategies developed for the stereoselective construction of natural complex decalin systems. It offers an insight into various synthetic targets and approaches and provides information for developments within the area of natural products as well as synthetic methodology.

Introduction

Diels-Alder reactions

Intermolecular Diels-Alder reaction

Intramolecular Diels-Alder reaction (IMDA)

Transannular Diels-Alder reaction (TADA)

Cyclization promoted by reaction of alkene/alkyne ( $\pi$ bonds) with electrophilic reagent (cation-like moieties)

Cationic reactions (or acid mediated reactions)

Metal mediated reactions

Intramolecular Friedel-Crafts alkylation

"Aliphatic Friedel-Crafts" reaction

Cationic reaction and/or aldehyde-ene reaction

Nucleophilic and anionic cyclization

Wieland-Miescher ketones

Michael and/or aldol reaction sequences

Allylation reaction

Anionic polycyclization reaction ("anionic Diels-Alder reaction")

Radical reactions

Miscellaneous pericyclic reactions (except Diels-Alder reactions)

Ring-closing metathesis (RCM)

Various reactions

Desymmetrization of meso-decalin

Aryne cyclization

Intramolecular Heck reaction

Intramolecular Pauson-Khand reaction
9 Conclusions

10 Notes and references

\section{Introduction}

The decalin ring system (or bicyclo[4.4.0]decane scaffold) is commonly found in a wide variety of natural products biosynthetically derived from isoprenoids (sesquiterpenoids and diterpenoids) and polyketides. This motif often correlates with highly multifunctionalized or architecturally complex groups, thereby demonstrating remarkable structural and functional diversity. The intricate structures and diverse biological activities of decalins have attracted many researchers around the world to investigate their chemical synthesis and further study their therapeutic potential. Since the elaboration of such complex skeletons remains a challenge, the design of new strategies for their stereoselective synthesis is still of great interest among organic chemists.

This review surveys the synthesis of natural cis- and transdecalin-type compounds, with emphasis on the recent total synthesis of multifunctionalized decalins. An overview of the methods developed for the construction of stereogenic centers embedded in the decalin ring of various natural compounds will be presented. The aim of this article is to highlight delineated examples of natural decalin total synthesis and relevant methods related to their achievement. A particular focus will be devoted to emerging strategies or areas which are ripe for further development, but also on more classical tactics which have reached impressive levels of understanding and implementation.

While there is no recent exclusive review on the synthesis of natural decalins, earlier reports on specific methods or synthetic approaches toward a particular family of compounds may overlap with this review. ${ }^{1-6}$ 
In general, decalin synthesis can be classified into two disconnection types (types I and II), according to the order of construction of the two fused cycles A and B. Type I starts with the elaboration of a cyclohexane derivative (corresponding to the cycle $\mathrm{A}$ or $\mathrm{B}$ ) and subsequent $\mathrm{C}-\mathrm{C}$ bond formations lead to the desired bicyclic system [AB]. Type II involves the simultaneous construction of the cycles A and B in a single step process (Scheme 1). Based on these two disconnection types, number of methods are likely to result in the synthesis of decalin motifs.

The major accesses to decalin systems involve (a) Diels-Alder reactions - both inter- and intramolecular, (b) nucleophilic and anionic cyclizations, and (c) cation- or radical-induced polyene cyclizations. Moreover, emergent methods are particularly attractive and able to offer great opportunities for rapid and

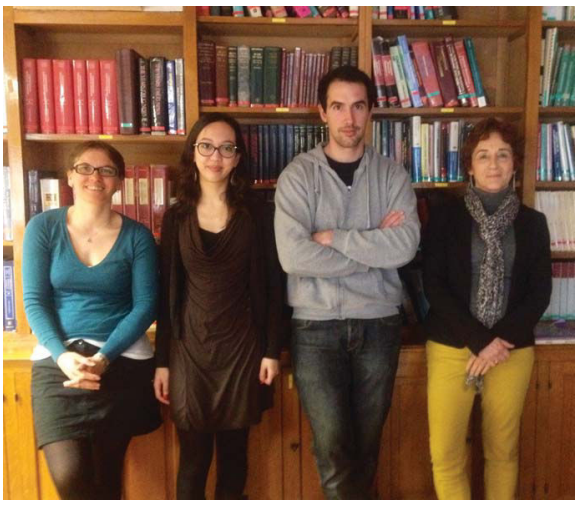

From left to right :

Marie-Isabelle Lannou, Sabrina

Dhambri, Geoffroy Sorin and Janick Ardisson
M.-I. Lannou worked as a PhD student under the supervision of Pr J.-L. Namy and Pr J.-C. Fiaud (University Paris Sud, Orsay) in the field of lanthanides chemistry (19992002). She then joined the team of Pr Enders in RWTH Aachen as a postdoctoral fellow (2003-2004), where

she focuses on the synthesis of crippowellins. Her project as Assistant Professor in Dr A. Pancrazi/Pr J. Ardisson team in Cergy Pontoise, allowed her to develop an approach towards the synthesis of sarcodictyines, then she got a position of Assistant Professor in Pr F. Mongin team in Rennes where she worked on zinc-ate complexes. In 2006, she joined the CNRS as a researcher in Dr A. Pancrazi/PrJ. Ardisson team in Cergy Pontoise and then moved to Paris (Pr J. Ardisson, UMR CNRS 8638, Paris Descartes University). Consequently, her research interests are various, from methodology in organometallic chemistry to total synthesis of natural products.

Geoffroy Sorin obtained his PhD in 2008 in the field of the synthesis and structure-activity relationship of huprine derivatives under the supervision of Pr P.-Y. Renard (IRCOF, Rouen). He pursued his career in Paris, as a post-doctoral fellow with Pr L. Fensterbank (University Pierre and Marie Curie) on the oxidation of alkyl trifluoroborates for tin-free radical chemistry, then with $\mathrm{Pr}$ J. Ardisson (Paris Descartes University) on the structural elucidation and synthesis of a new polyketide, hemicalide. In 2011, he got a position of Assistant Professor in Pr J. Ardisson team in Paris (UMR CNRS 8638, Paris Descartes University). His research interests mainly focus on the total synthesis of natural products and new synthetic methods.

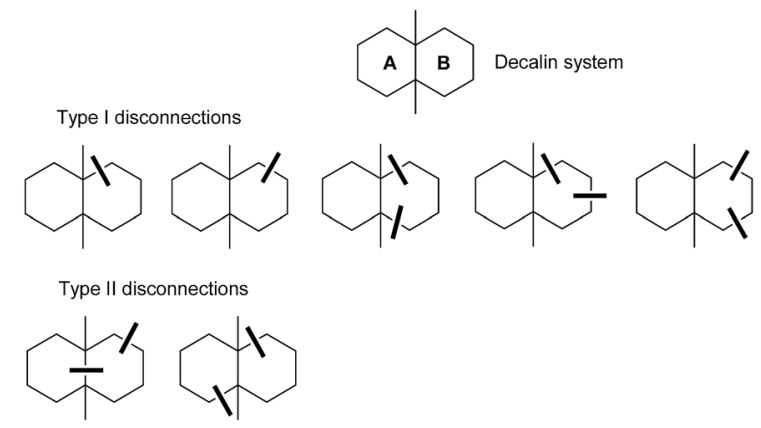

Scheme 1 Decalin synthesis according to type I and II disconnections of the review.

selective construction of these motifs. For this reason, the present review is divided into sections corresponding to the different methods mentioned above.

\section{Diels-Alder reactions}

The Diels-Alder (DA) cycloaddition has proven to be one of the most powerful and efficient transformation for accessing sixmembered cycles, with high chemo-, regio- and stereoselectivity in an atom-economic manner. Since its discovery by Otto Diels and Kurt Alder in 1928, ${ }^{7}$ the DA reaction has undergone intensive development and has become a mainstay in organic synthetic methodologies. Moreover, the DA transformation has been frequently used as key step for a significant number of elegant achievements in the field of complex biologically active molecules and natural product synthesis. ${ }^{4-6,8-19}$

Two versions can be employed: the inter- and the intramolecular reactions. Both approaches are presented in the following sections.

\subsection{Intermolecular Diels-Alder reaction}

The intermolecular Diels-Alder reaction has been widely applied in the construction of cis-decalin frameworks.

Historically, the use of quinones as dienophiles is highly significant, being the very first example investigated by Diels and Alder. Interestingly, the trend in the use of quinones was maintained throughout the early decades following the seminal report by Diels and Alder since their electron-deficient nature

Pr J. Ardisson received her PhD in 1984 from the University of Orsay (Paris 11) where she worked on the total synthesis of Aspidosperma alkaloids, under the supervision of Pr J. Poisson and $\mathrm{Dr}$ N. Kunesch. She joined Pr M. Julia team (ENS, Paris) as a postdoctoral fellow to develop a total synthesis of avermectins (19841987) and then returned to the faculty of Pharmacy of ChâtenayMalabry (Paris 11) as Assistant Professsor. She then joined the University of Cergy-Pontoise as full Professor and is now full Professor at the Paris Descartes University. Her research interests include total synthesis of bioactive natural products. 
makes them remarkable partners for both electron-rich and electron-neutral dienes. Furthermore, the chemical motif of quinones easily allows subsequent transformations of the DA adduct. ${ }^{9}$ Two recent examples were selected to illustrate these reactions.

A total synthesis of the triterpenoid natural product perovskone was reported in 2011 by Majetich. ${ }^{20}$ The strategy was based on the biomimetic creation of four rings, five bonds and six stereocenters in a one-pot procedure by means of a DA addition involving (E)- $\beta$-ocimene 2 and the icetaxone-like tricyclic quinone $\mathbf{1}$ followed by a triple cyclization (Scheme 2). Thereby, under boron trifluoride diethyl etherate catalysis, optically active quinone 1 was converted to perovskone in 50\% yield, through a polycyclization cascade.

A one pot Diels-Alder/Michael cascade has been developed by Greck in 2013 toward the formation of tricyclic ring systems 5 frequently encountered in various natural products, such as valeriananoid $\mathrm{A}$, penicillinone $\mathrm{A}$ and atropurpuran. ${ }^{21}$ In the presence of a bulky aminocatalyst like 6 and $\mathrm{PhI}(\mathrm{OAc})_{2}$ as oxydant, it has been observed that the reaction between dienal 3 and hydroquinone $\mathbf{4}$, two readily accessible planar structures, stereoselectively leads to functionalized tricyclic architectures like 7 and 8 (Scheme 3).

Platensimycin and platencin are potent bacterial type-II fatty acid biosynthesis inhibitors, isolated from the same microorganism. Structurally, these compounds bear the same side chain; however, they are characterized by unique structural features in their polycyclic cage-like moieties. Platensimycin has a tetracyclic framework including a cyclic ether while platencin has a only
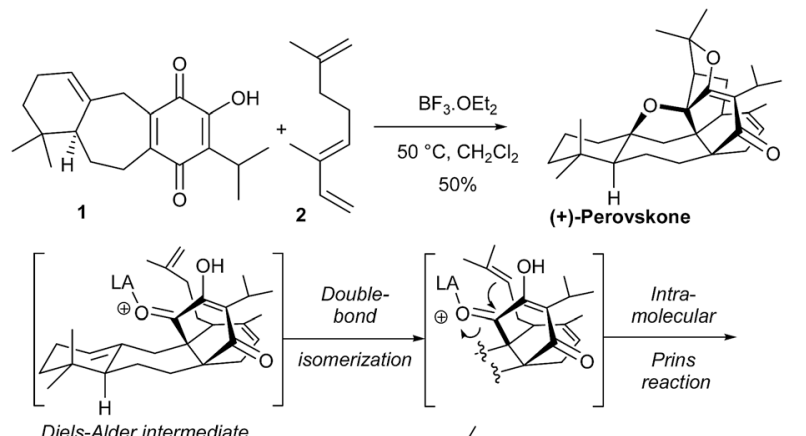

Diels-Alder intermediate
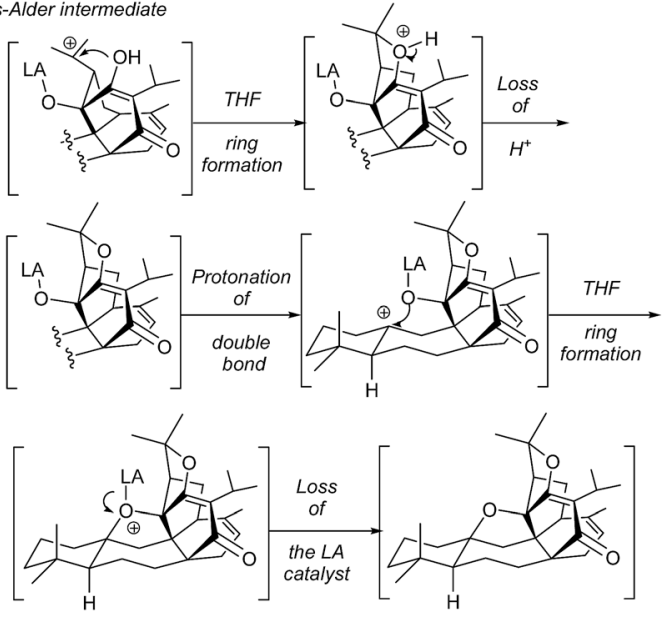

Scheme 2 Majetich's total synthesis of perovskone.
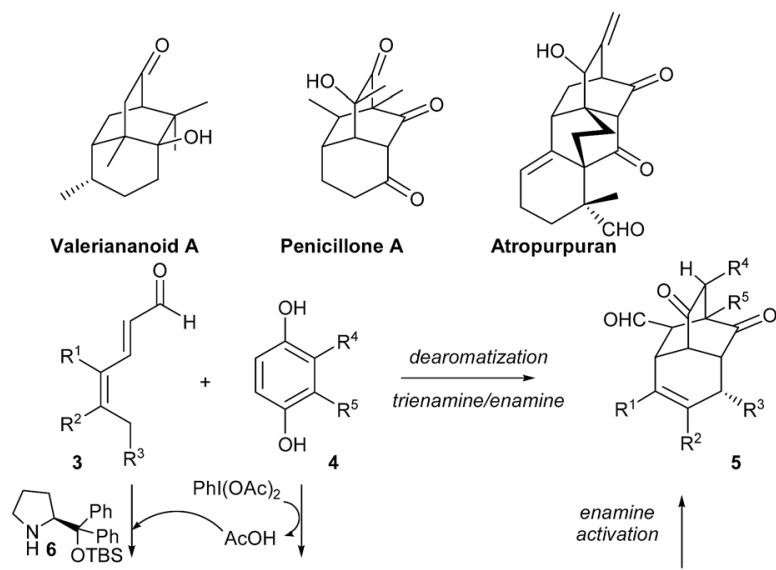

(reaction

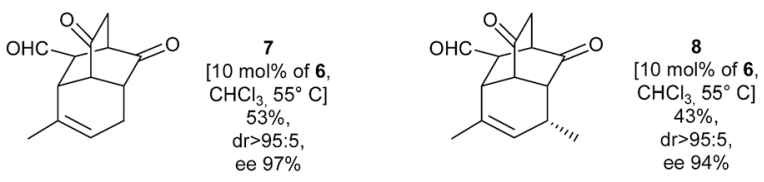

Scheme 3 Greck's method for formation of tricyclic ring systems.

carbon-containing tricyclic skeleton. Biosynthetic studies have revealed that the polycyclic unit could arise from a similar entkaurenoid type intermediate 9 (Scheme 4). ${ }^{3,22}$

The tricyclic ent-kaurenoid $( \pm)-\mathbf{1 2}$ has been constructed by Zhang through a Diels-Alder reaction/carbocyclization cascade. ${ }^{23}$ The strategy involves a Lewis acid induced DielsAlder cycloaddition between enone 10 and diene 11. Then, the resulting silyl enol ether $( \pm)$-13 undergoes intramolecular carbocyclization with the alkyne to form the tricyclic ent-kaurenoid moiety $( \pm)-12$ in a one-pot manner. This sequence requires a mild Lewis acid $\left(\mathrm{ZnBr}_{2}\right)$ that can form first a $\sigma$-complex with enone 10 in order to promote the DA cycloaddition, then a $\pi$ complex with intermediate $( \pm)$-13 that triggers the carbocyclization without causing early cleavage of silyl enol ethers. Noteworthy, cyclic adduct $( \pm)-\mathbf{1 2}$ has been successfully used as a common building block for the formal synthesis of racemic platencin and platensimycin, by means of elaboration of Nicolaou's and Snider's intermediates (Scheme 56). ${ }^{\mathbf{2 4 , 2 5}}$

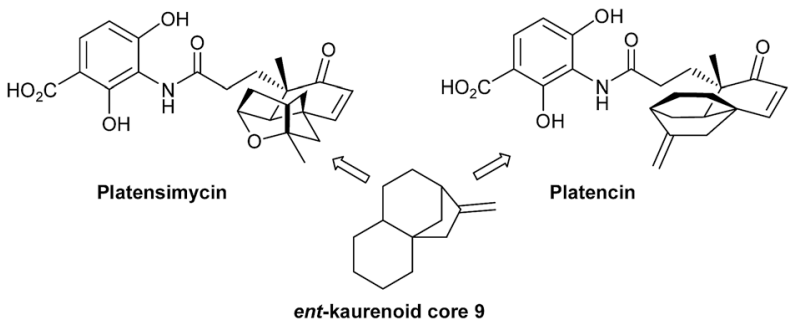

Scheme 4 Ent-kaurenoid biosynthetic precursor of platensimycin and platencin. 


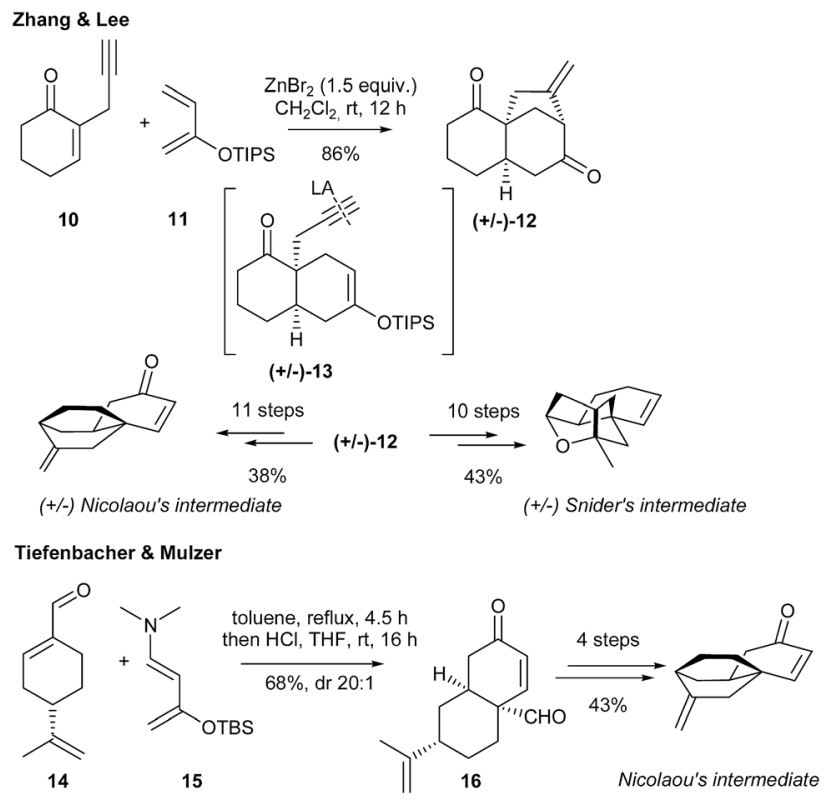

Scheme 5 Zhang, Lee, Tiefenbacher and Mulzer syntheses of Nicolaou and Snider intermediates of platencin and platensimycin.

Besides, Tiefenbacher and Mulzer have developed a five step stereocontrolled route to the Nicolaou's intermediate, using a natural terpene, (-)-perillaldehyde $\mathbf{1 4}$, as a chiral template (Scheme 5). ${ }^{26}$ The synthetic scheme involves a DA reaction between 14 and the Rawal diene 15 to construct the decalin core 16 in a $20: 1$ diastereomeric ratio.

Towards the assembly of the tetracyclic system of rhodexin A, a novel cardiac glycoside with potent antiproliferative activity $\left(\mathrm{IC}_{50}\right.$ of $19 \mathrm{nM}$ ), Jung reported a very hindered inverseelectron-demand Diels-Alder reaction. ${ }^{27,28}$ In a first simplified racemic series, the cycloaddition reaction between the diene $( \pm)-\mathbf{1 7}$ and the dienophile $( \pm)-\mathbf{1 8}$ occurs through the most favored exo transition state $\mathbf{I}$ to form the expected tricyclic system ( \pm )-19 in $87 \%$ yield as a $2: 1$ mixture of diastereomers at the secondary silyl ether group. Unfortunately, the reaction between 20 and 21, leading directly to the tetracyclic core of rhodexin A, proceeds with undesirable facial selectivity and results in the C8 diastereomer 22 (Scheme 6). A stepwise cycloaddition process, involving a Mukaiyama-Michael reaction followed by a vinylogous Mukaiyama-Michael intramolecular trapping, through transition state II, may be responsible for this lack of selectivity.

\subsection{Intramolecular Diels-Alder reaction (IMDA)}

The IMDA reaction has also been extensively utilized as a powerful strategy for the efficient construction of decalin systems. Many creative IMDA strategies and transannular versions of IMDA (TADA), have been featured in natural product synthesis. Combining IMDA cycloaddition with other organic reactions in a one-pot manner provides very interesting methods for the synthesis of fused and bridged polycyclic compounds. A significant number of elegant synthetic achievements have been reported.
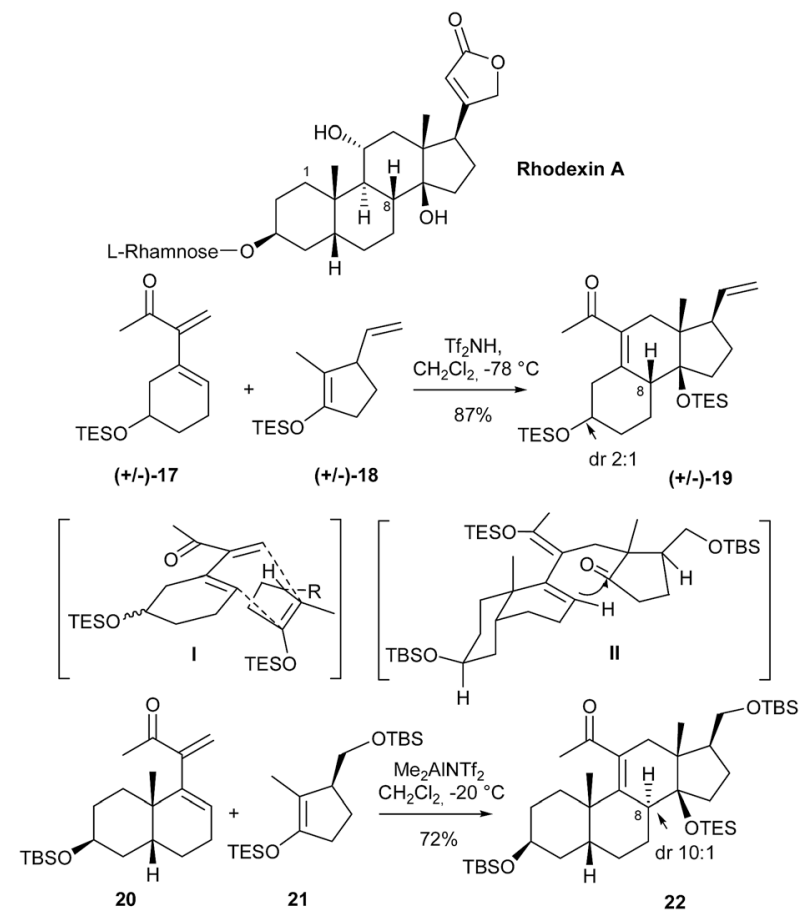

Scheme 6 Hindered inverse-electron-demand DA reaction towards rhodexin synthesis.

The total synthesis of racemic amphilectene, a marine nanomolar antimalarial agent has been recently described by Shenvi in seven steps. ${ }^{29}$ The synthesis relies on a new dendrimeric variant of the Danishefsky's diene 23. By inducing a diene transmissive Diels-Alder sequence (DTDA) i.e. two successive cycloaddition reactions, ${ }^{30} 23$ yields the tricyclic system $( \pm)-26$ in a single step. Intermolecular cycloaddition between 23 and $\mathbf{2 4}$ occurs at ambient temperature, and subsequent addition of 5 $\mathrm{mol} \% \mathrm{Yb}(\mathrm{OTf})_{3}$ generates the intermediate cross-conjugated enone 25. This compound then undergoes the second DielsAlder cycloaddition (in an intramolecular version) upon heating
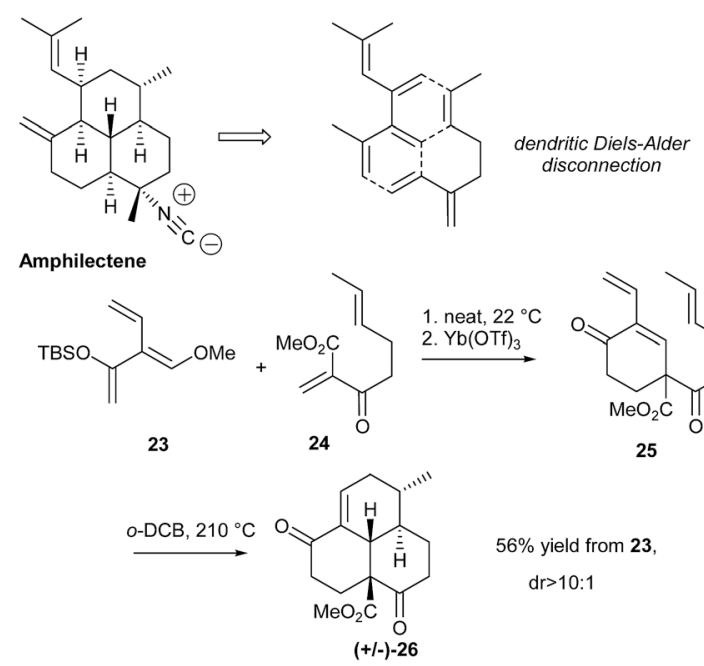

Scheme 7 Shenvi's total synthesis of amphilectene. 
in $o$-dichlorobenzene in a microwave reactor. Finally, tricycle $( \pm)$-26 can be isolated in 56\% yield with a high selectivity (d.r. > $10: 1)$. The sequence $(23+\mathbf{2 4} \rightarrow( \pm)-26)$ can also be conducted in one pot, however in lower yield (31\%), since the presence of $\mathrm{Yb}(\mathrm{OTf})_{3}$ generates competitive decomposition (Scheme 7).

The first total synthesis of (+)-kalihinol A, an antimalarial diterpenoid isolated from a marine sponge has been achieved by Miyaoka. ${ }^{31}$ The strategy features the construction of a cis-decalin ring by IMDA reaction, followed by cis-trans isomerization of the decalin, and subsequent functionalization of the trans-decalin system. Triene $\mathbf{2 8}$ has been synthesized from optically active diol 27 in $20 \%$ yield over 19 steps. Oxidation of 28 with Dess-Martin periodinane resulted in the spontaneous formation of $\mathrm{cis}$-decalin 29 as the sole product in 99\% yield, through endo-selective IMDA reaction. Thereafter, 29 has been transformed into epoxide $\mathbf{3 0}$. Subsequent treatment of $\mathbf{3 0}$ with $\mathrm{NaN}_{3}$ gives a mixture of transdecalin trans-31 and cis-decalin cis-31 (trans-31/cis-31 = $2: 1$ ) in 95\% yield. A base equilibration of cis-31 allows the formation of a new mixture of trans-31 and cis-31 (trans-31/cis-31 = $3: 2$ ) in 99\% yield. The desired trans-decalin trans-31 is finally converted into the target molecule (Scheme 8).

Evans has reported a total synthesis of ent-himgaline, the enantiomer of a unique cage-structure gabulimima alkaloid. ${ }^{32}$ To elaborate the bicyclo[3.2.1] octane skeleton of ent-himgaline, linear polyketide precursor 33 undergoes a succession of intramolecular bond constructions. Firstly, an auxiliarycontrolled IMDA cycloaddition of triene 33, prepared in a five step sequence from aldehyde 32, is achieved using $\mathrm{Me}_{2} \mathrm{AlCl}$; the desired trans-decalin 34 is obtained in $81 \%$ yield as a single diastereomer. Afterwards, intramolecular Michael addition allows the construction of the cyclopentane moiety $(35 \rightarrow 36)$. Finally, imine aldol addition from the keto-imine $\mathbf{3 7}$ delivers $\mathbf{3 8}$ which undergoes $\mathrm{N}$-conjugate addition providing a straightforward access to ent-himgaline (Scheme 9).

Artemisinin, an endoperoxide sesquiterpene natural product, has been the subject of synthetic, mechanistic and pharmacological studies due to its antimalarial properties. Arteannuin B and dihydro-epi-deoxy arteannuin B, two other important compounds isolated from the same plant, are the biosynthetic precursors of artemisinin. An asymmetric synthesis of $\mathrm{C}_{10}$-epi-dihydro-epi-deoxy arteannuin $\mathrm{B}$ has been achieved by Gosh employing an IMDA reaction of the sugar embedded decatrienone $\mathbf{4 1} .^{33}$ Trienol $\mathbf{4 0}$ is first prepared from aldehyde 39 in $44 \%$ yield over six steps. Next, oxidation of $\mathbf{4 0}$ with Dess-Martin periodinane (DMP) allows spontaneous cycloaddition of the resulting enone $\mathbf{4 1}$ to afford the trans-decalin derivative $\mathbf{4 2}$ as the sole product in $85 \%$ yield. Noteworthy, the corresponding regioisomer 43 , when subjected to DMP oxidation under the same conditions, affords enone $\mathbf{4 4}$. Subsequent heating in toluene at $160{ }^{\circ} \mathrm{C}$ for nearly $40 \mathrm{~h}$ is required for the IMDA reaction to proceed, thus delivering the cis-decalin derivative $\mathbf{4 5}$ in $70 \%$ yield. Finally, the IMDA reaction of trienone 47 (prepared from trienone 46 devoid of any Me group on the diene moiety), leads after $12 \mathrm{~h}$ of heating in toluene at $140{ }^{\circ} \mathrm{C}$ to a mixture of trans- and cis-decalins 48 in $64 \%$ and $16 \%$ yields respectively. Consequently, it appears that the stereochemical outcome of IMDA reactions involving decatrienones 41, 44 and $\mathbf{4 7}$ is strongly dependent on the position of the Me substituent on the diene moiety. Thereby, Gosh has postulated that observed results may be attributed to steric interactions in the transition states (Scheme 10).

Trauner has described a short and asymmetric entry to the core structure of the cordiachromes, an unusual class of

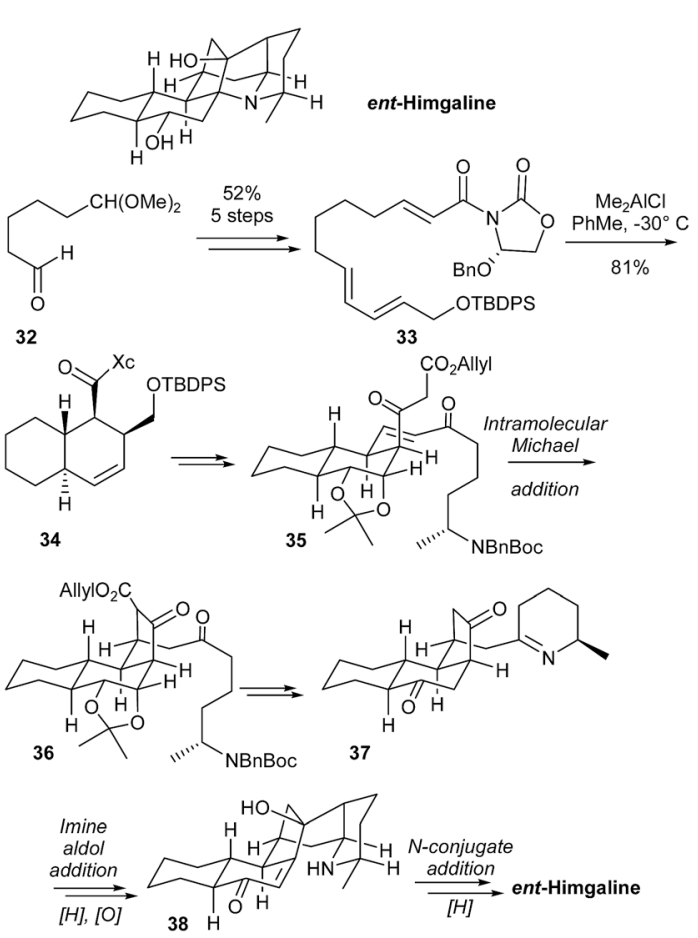

Scheme 9 Evans' total synthesis of ent-himgaline. 


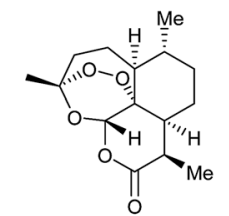

(-)-Artemisinin

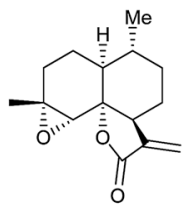

$(-)$-Arteannuin B

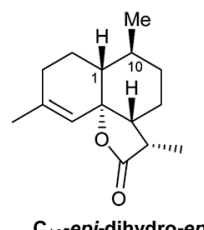

$\mathrm{C}_{10}$-epi-dihydro-epideoxy arteannuin $B$

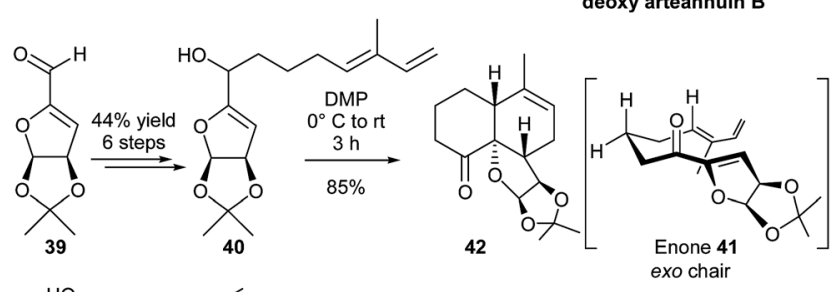

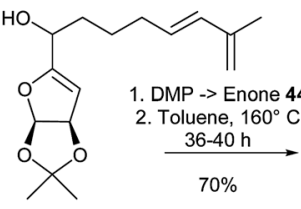

43

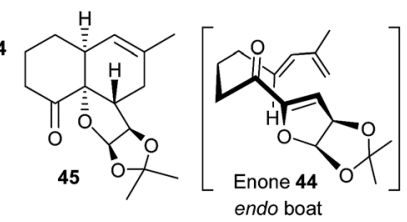

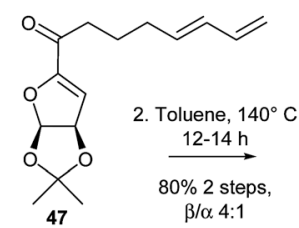

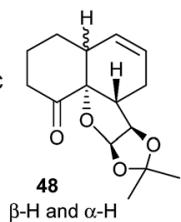

Scheme 10 Gosh's total synthesis of $\mathrm{C}_{10}$-epi-dihydro-epi-deoxy arteannuin B.

meroterpenoids characterized by a hydroanthracene skeleton. ${ }^{34}$ For an access to (-)-iso-glaziovianol, the strategy is based on an intramolecular vinyl quinone Diels-Alder (VQDA) reaction with neutral electron demand. The synthesis starts with the preparation of the tertiary allylic ether $\mathbf{5 0}$ by regio- and enantioselective opening of the racemic vinylepoxide $( \pm)-49$ in a dynamic kinetic resolution under Trost conditions. ${ }^{35}$ The key step of the approach involves the in situ formation of vinyl quinone $\mathbf{5 2}$ from hydroquinone 51. Quinone 52 rapidly undergoes VQDA reaction at room temperature via the endo transition state $\mathbf{I}$, followed by nucleophilic interception of the resulting isoquinone methide 53. Further oxidation of hydroquinone $\mathbf{5 4}$ upon work-up affords the tetracyclic quinone $\mathbf{5 5}$ in $39 \%$ overall yield (Scheme 11).

The intramolecular Diels-Alder reaction of furans is of great importance in organic synthesis. Hence, the resulting oxygenbridged systems are valuable precursors to functionalized polycyclic compounds. In this context, a highly efficient palladium-catalyzed allenylation/intramolecular Diels-Alder reaction of furans with propargyl carboxylates has been developed by $\mathrm{Li}^{36}$ This methodology offers rapid access to polycyclic compounds in high yields. Thus, the reaction of propargyl carbonates 56 with boronic acids 57, performed by using $\mathrm{Pd}\left(\mathrm{PPh}_{3}\right)_{4}$ and $\mathrm{Cs}_{2} \mathrm{CO}_{3}$ at $100{ }^{\circ} \mathrm{C}$, efficiently delivers polycyclic compounds 58. The authors proposed the following catalytic pathway: oxidative addition of propargyl carbonate 56 to $\operatorname{Pd}(0)$ complex generates an allenyl palladium intermediate, which undergoes transmetalation with organoborane 57. After<smiles>CC12Cc3c(O)ccc(O)c3CC1(C)[C@H](O)CCC2=O</smiles>

(-)-iso-Glaziovianol

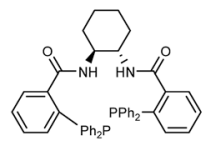

S,S-DACH ligand
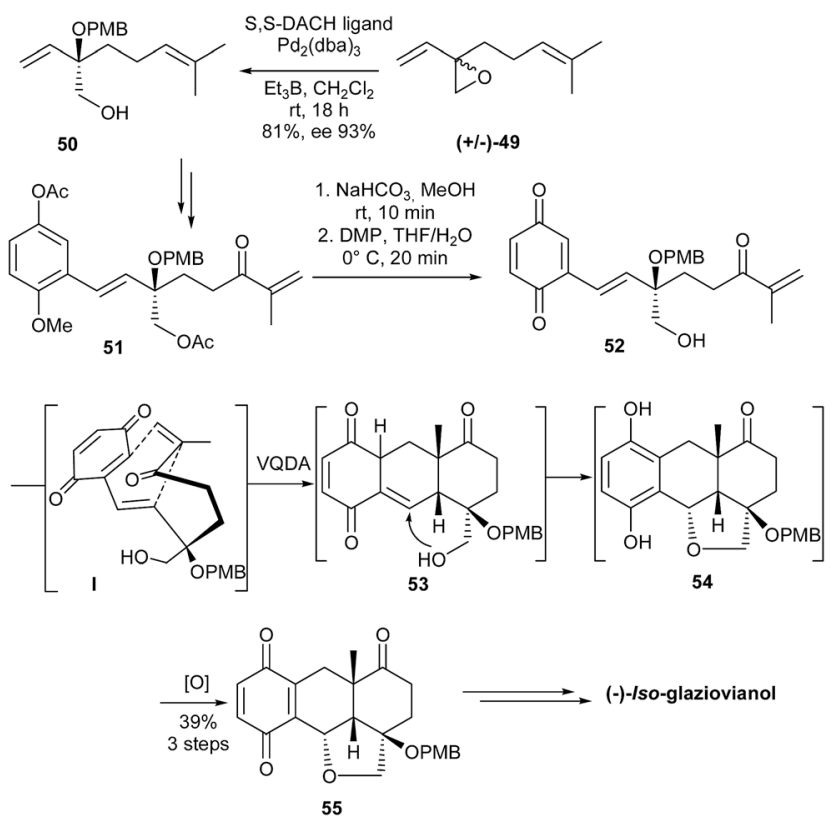

Scheme 11 Trauner's total synthesis of iso-glaziovianol.
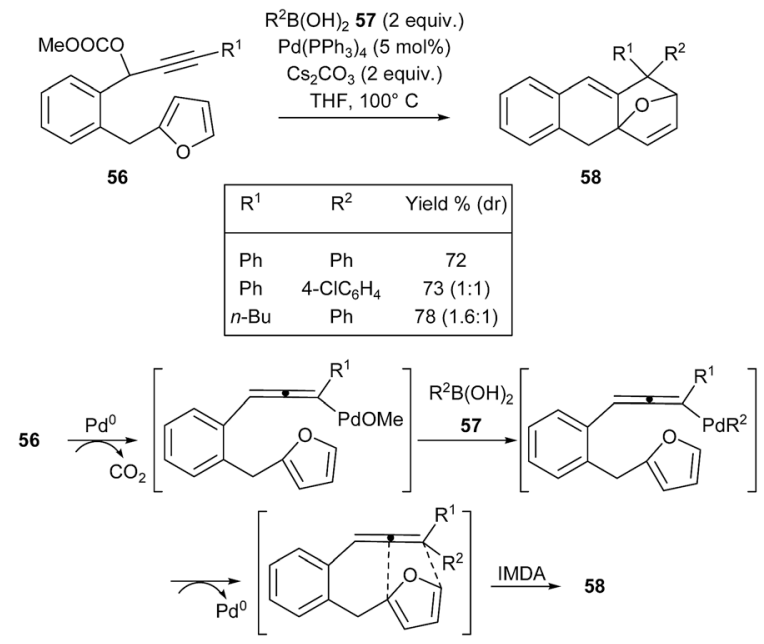

Scheme 12 Intramolecular Diels-Alder reaction of furans

reductive elimination, intramolecular Diels-Alder reaction furnishes desired product $\mathbf{5 8}$ (Scheme 12).

\subsection{Transannular Diels-Alder reaction (TADA)}

Transannular Diels-Alder (TADA) reactions are an intriguing subgroup of IMDA reactions. These transformations, that usually display high level of chemo-, regio-, and stereoselectivity, are powerful ways to generate complexity from relatively simple starting materials. Starting from a macrocycle, TADA processes 


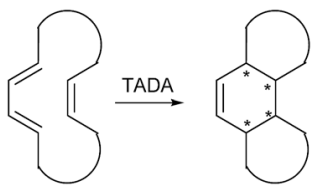

Scheme 13 General scheme for TADA reactions.

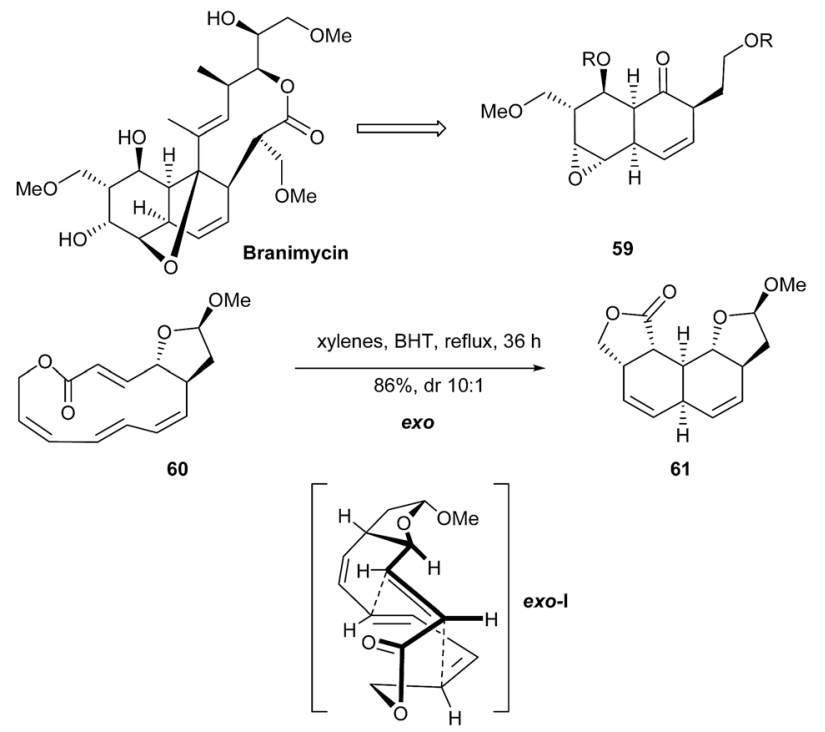

Scheme 14 Mulzer's synthetic approach to branimycin.

can theoretically generate three rings, two carbon-carbon bonds, and four stereocenters with a perfect control of both relative and absolute stereochemistry (Scheme 13). ${ }^{16}$

As a recent contribution to the field of TADA reactions, a synthetic approach to the antibiotic branimycin described by Mulzer is reported. ${ }^{37}$ The key disconnection leads to the cisdehydrodecalone core 59, which has been targeted by means of a TADA reaction from the macrolactone $\mathbf{6 0}$. Therefore, $\mathbf{6 0}$ is heated at reflux in xylenes for $36 \mathrm{~h}$ to provide the required product $\mathbf{6 1}$ in 86\% yield through exo-I transition state (Scheme 14).

Due to its extreme efficacy to simultaneously create several new bonds and stereocenters, electrophilic $\pi$ activation proved to be as powerful as Diels-Alder reactions. This method has thus inspired numbers of decalin synthesis strategies and will be the purpose of the next part of this review.

\section{Cyclization promoted by reaction of alkene/alkyne ( $\pi$ bonds) with electrophilic reagent (cation-like moieties)}

Sixty years ago, Stork and Eschenmoser first delineated the cation- $\pi$ cyclization hypothesis to account for the formation of various decalins and polycyclic scaffolds in Nature. ${ }^{38}$ Since then, many investigators have developed selective methods to perform such reactions in the laboratory.
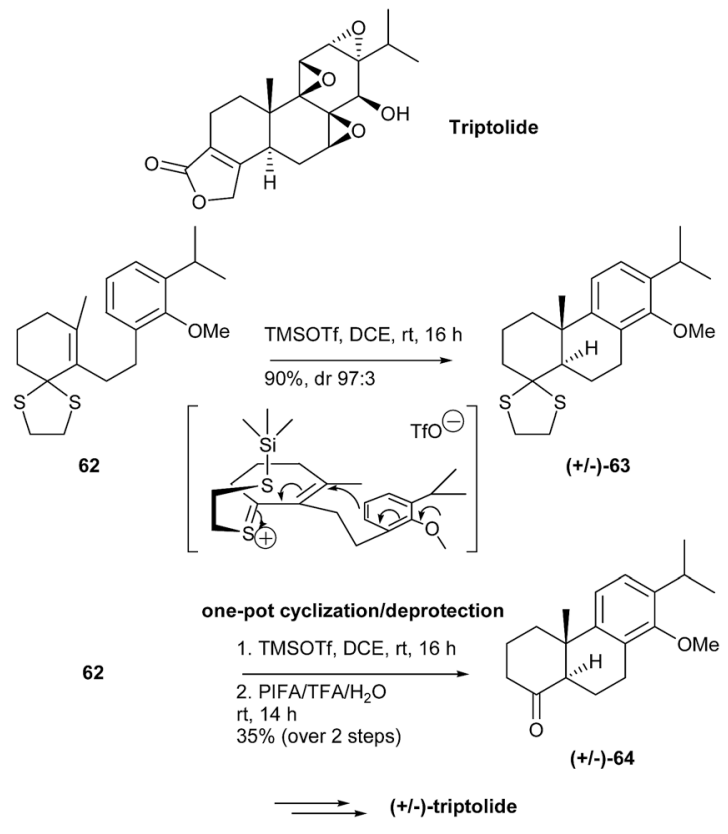

Scheme 15 Baati's total synthesis of racemic triptolide.

Nevertheless, the potential highlighted by the cation $-\pi$ cyclization, as the principal $\mathrm{C}-\mathrm{C}$ bond forming reaction in terpene biosynthesis, suffers from a lack of synthetic tools for mimicking this reaction. The main reason for this deficiency is the high reactivity of cationic intermediates which can also react in nonproductive fashions. ${ }^{39}$ In this review, several examples involving catalyst control of these cation-olefin reactions and its application to natural decalin synthesis are reported.

\subsection{Cationic reactions (or acid mediated reactions)}

In a synthesis of triptolide, Baati has developed an efficient and highly diastereoselective cationic 6-endo-trig cyclization of 2alkenyl-1,3-dithiolane $\mathbf{6 2}$ for the construction of trans-decalin $( \pm)-63 .^{40,41}$ The 2-alkenyl-1,3-dithiolane core acts as a latent initiator and it is suggested that the thioketal temporarily opens under the influence of TMSOTf, triggering the cationic 6-endo-
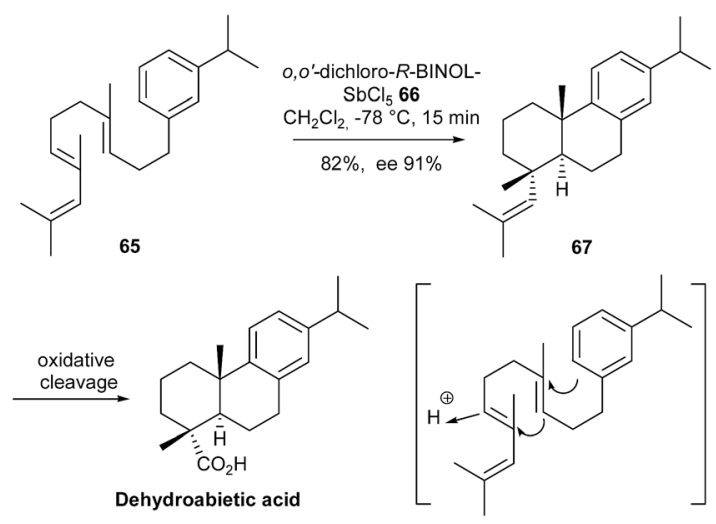

Scheme 16 Corey's total synthesis of dehydroabietic acid. 
trig cyclization. A one-pot cyclization followed by in situ 1,3dithiolane deprotection directly affords the ketone ( \pm -64, permitting the completion of the shortest formal synthesis of racemic triptolide (Scheme 15).

Corey has recently reported that the $1: 1$ complex of $o, o^{\prime}$ dichloro- $R$-BINOL and $\mathrm{SbCl}_{5}(\mathbf{6 6})$ is able to initiate the enantioselective cationic polycyclization of polyunsaturated substrates at a predictable $\pi$-bond which may be either terminal or internal. ${ }^{42,43}$ This strategy depends on the modulation of the relative proton affinity of the $\pi$-bonds within the substrate to control the initiating site of cyclization. The reaction occurs rapidly and efficiently at $-78{ }^{\circ} \mathrm{C}$, demonstrating the very strong acidity of the complex and the high selectivity in the protonation of the olefinic linkage. This methodology has proved to be useful in the enantioselective synthesis of several natural products. For instance, dehydroabietic acid could be produced expeditiously and enantioselectively via the transformation of triene 65 into tricyclic compound 67, as outlined in Scheme 16.

Another example of the use of the same chiral catalyst $\mathbf{6 6}$ for the initiation of cationic cyclization at an internal $\pi$-bond is illustrated in Scheme 17. In a single step, the acetylenic olefin 68 could afford the tricyclic product 69 in $75 \%$ yield and $87 \%$ ee. The sequence is clearly initiated by protonation of the internal olefinic $\pi$-bond to form a bicyclic acetylene which then undergoes a second (and slower) cyclization to generate the tricycle 69; this product is of interest as a close analogue of the pseudopterosin core. The success of this double annulation process is due to the lower proton affinity of the triple bond relative to the double bond.

An unusual oxidative cationic polycyclization process, developed by Canesi, enables rapid access to decalin systems present in several natural products such as cassaic acid, by activation of phenol derivatives. ${ }^{44}$ Oxidative activation transforms phenols into highly reactive electrophilic species ("aromatic ring umpolung") which can be intercepted in an intramolecular fashion by $\pi$ bonds, thus initiating a diastereoselective polycyclization leading to bi- or tricyclic cores. For instance, $(E)$-phenol 70 reacts under $\mathrm{PhI}(\mathrm{OAc})_{2}$ conditions in hexafluoroisopropanol (HFIP) which functions as both nucleophile and solvent, to provide the tricyclic product $( \pm)-\mathbf{7 1}$, with a total stereocontrol (Scheme 18).
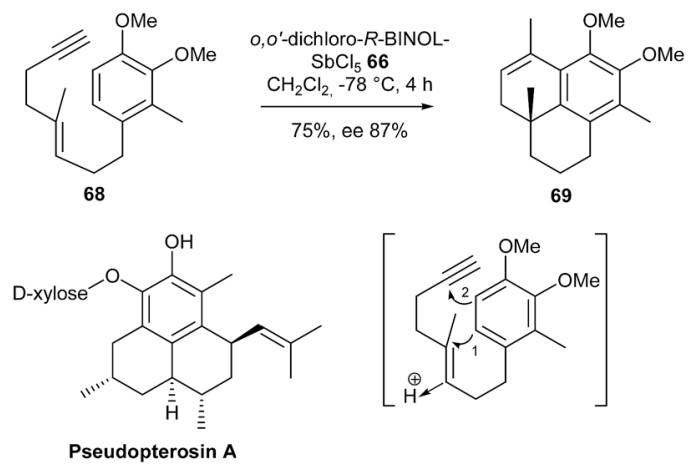

Scheme 17 Corey's synthesis of analogue of pseudopterosin.

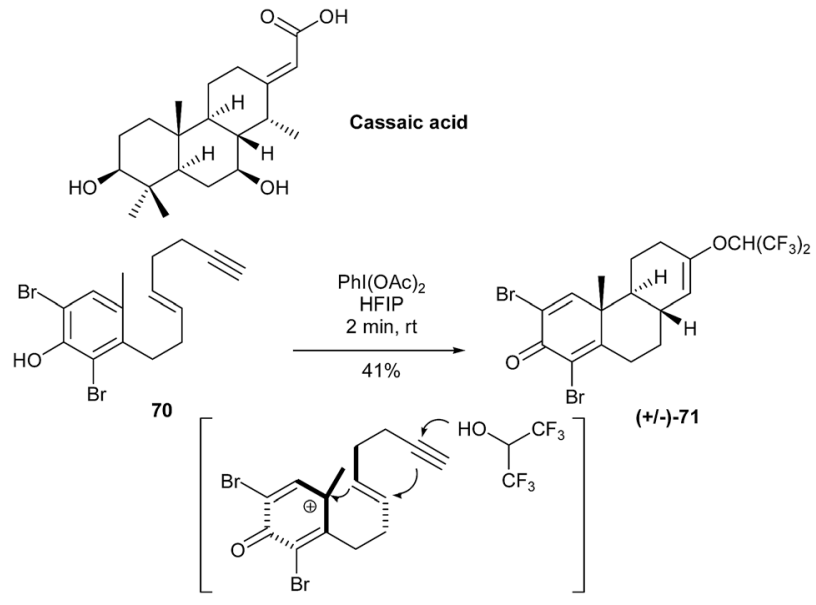

Scheme 18 Canesi's oxidative cationic polycyclization process.

Recently, Snyder has developed a procedure capable of mimicking the direct, asymmetric, halonium-induced cation- $\pi$ cyclization commonly used in Nature to elaborate complex architectures, in the presence of chiral mercury(II) complexes. ${ }^{45}$ For instance, polyene 72 smoothly undergoes cyclization to generate an organomercurial intermediate. Subsequent bromination diastereoselectively affords the tricyclic product $\mathbf{7 4}$ in $79 \%$ yield and $72 \%$ ee using ligand 73 ; recrystallization leads to 74 in $53 \%$ yield and $99 \%$ ee (Scheme 19). This process has been applied to the asymmetric total synthesis of the natural product 4-iso-cymobarbatol.

\subsection{Metal mediated reactions}

While Lewis and Brønsted acid electrophiles are able to activate olefins towards nucleophilic attack, these species can however give nonselective reactions. Substrates might be prone to rearrangement or highly sensitive to reaction conditions, which constitutes major drawbacks. Thus, very selective complexes have to be designed in order to suppress above-mentioned side reactions.

In this context, electrophilic Pt(II) complexes efficiently initiate the cation-olefin reaction by first coordinating the less substituted alkene.

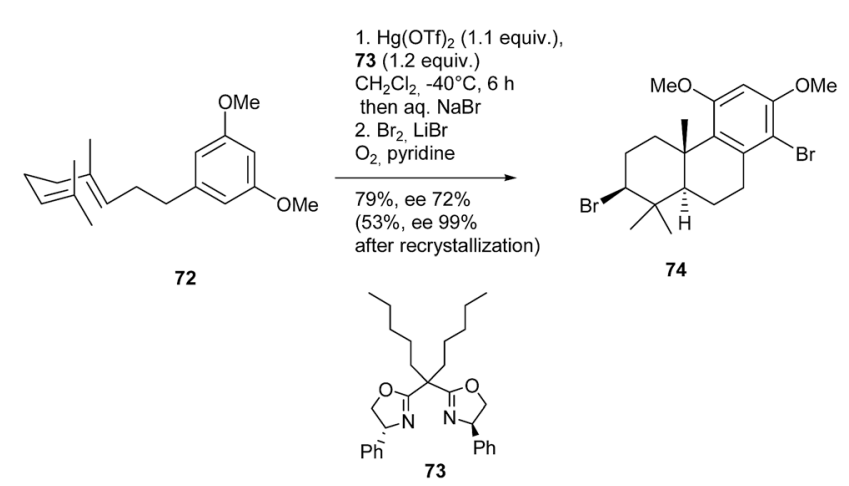

Scheme 19 Snyder's asymmetric halonium-induced cation- $\pi$ cyclization. 
Over the last years, Gagné has extensively explored platinum catalyzed cascade cyclization of polyenic systems. ${ }^{39,46,47} \mathrm{He}$ has initiated his studies by examining the cyclization of phenolic triene $\mathbf{7 5}$ in the presence of dicationic platinum complex $\mathbf{7 6}$. The formation of tetracycle $( \pm)-77$ clearly establishes that the least substituted alkene is the better ligand for the Pt(II) initiator (Scheme 20).

Very recently, Gagné has evidenced the applicability of this process to polyene cascade that terminates with an alkene instead of a protic group. These biomimetic polyene cascades are disadvantaged since alkenes are inherently poorer stabilizers of carbocations than heteroatoms, and because the olefinic protons do not become acidic until the carbocation has been completely formed. Despite these difficulties, Gagné has reported a very powerful Pt catalyzed alkene-terminated cationolefin cascade by means of a tridentate NHC Pt complex (79) which is not only sufficiently electrophilic to initiate the cation olefin cyclization but also electron-rich enough to undergo rapid protodemetalation. For instance, this process leads to an efficient and highly diastereoselective cyclization of triene $\mathbf{7 8}$ into bicycle $( \pm)-\mathbf{8 0}$, and tetraene 81 into tetracycle $( \pm)-82$ (Scheme 20).

Initiating polycyclization reactions through selective activation of an alkyne offers the potential advantage of circumventing undesired reactions resulting from nonselective alkene activation. In this field, Toste has evaluated the use of chiral phosphine-gold(I) complexes in a 6-endo-dig initiated polycyclization of 1,5 -enynes. ${ }^{48}$ For example, employing an electron-

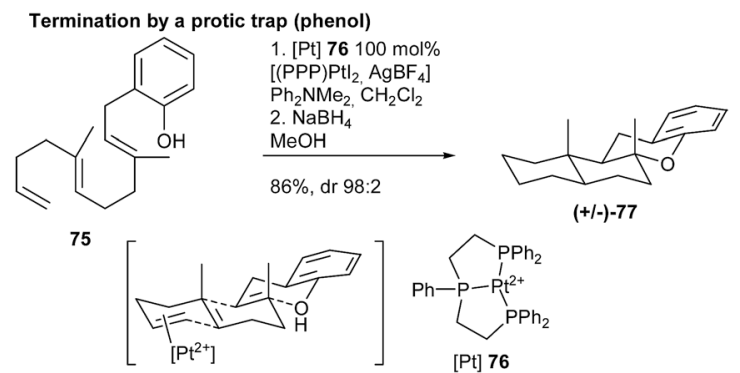

Termination with a non-protic group
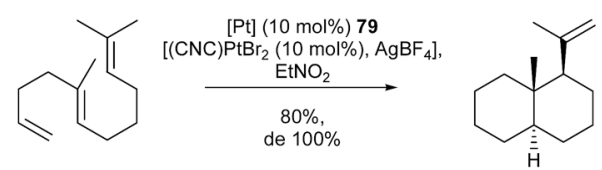

78

$(+/-)-80$

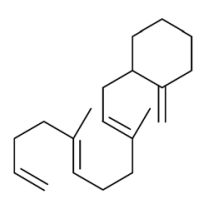

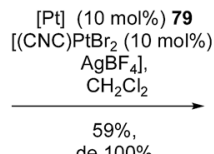

de $100 \%$

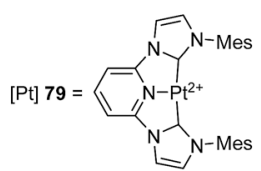

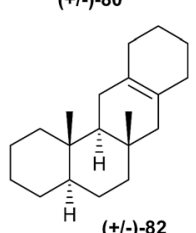

H $(+/-)-82$ enic systems.

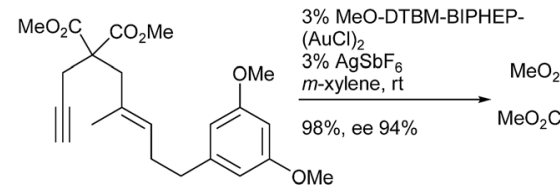

83

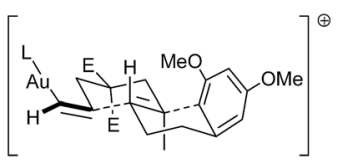

Scheme 21 Toste's polycyclization reactions.

rich aryl group as a nucleophile allows the enantioselective formation of the tricyclic system 84 from enyne 83 (Scheme 21).

Interestingly, Trost has reported an access to decalin cores through cycloisomerization of enynes containing cyclic olefins. ${ }^{49}$ By using distinct ruthenium and palladium catalysts, decalins with dichotomous stereochemical outcomes can be synthesized: trans-fused 1,4-dienes are obtained with ruthenium complexes while cis-fused diastereomers are formed under palladium catalysis. For example, substrate $\mathbf{8 5}$ featuring a methyl ester at the alkyne terminus, respectively affords the trans- and cis-decalin $( \pm)-86$ and $( \pm)-87$, under ruthenium and palladium catalysis (Scheme 22).

Under ruthenium catalysis, the reactivity can be rationalized by an initial allylic $\mathrm{C}-\mathrm{H}$ insertion mechanism, wherein the nature of the carboruthenation step is similar to the conjugate addition of a metal-alkyl species to an unsaturated carbonyl. Therefore, the reaction cannot occur if the alkyne is not a 1,4acceptor. In parallel, the cis-selectivity observed in the palladium-catalyzed cycloisomerization can be explained by a mechanism in which the metal is directed towards the same
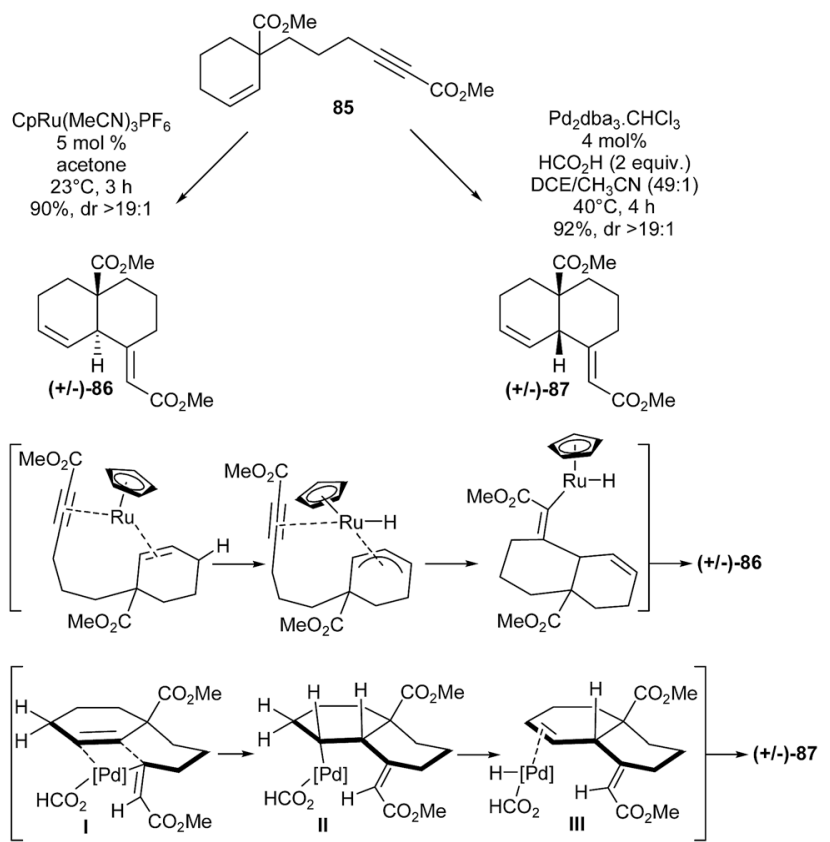

Scheme 22 Trost's cycloisomerization of enynes containing cyclic olefins. 
side of the ring as the alkyne. The active catalyst is generated by oxidative insertion of $\operatorname{Pd}(0)$ into $\mathrm{HCO}_{2} \mathrm{H}$ to lead to a classical Pd(II) species, which, through hydrometallation of the alkyne, delivers vinylpalladium species I. Intramolecular binding and insertion of the olefin then provides intermediate II and subsequent $\beta$-hydride elimination affords the 1,4-diene III (Scheme 22).

\subsection{Intramolecular Friedel-Crafts alkylation}

A convergent route has been developed by Yang to synthesize the unnamed antifungal tricyclic $o$-hydroxy- $p$-quinone methide diterpenoid 88 structurally related to taxodione. ${ }^{50} \mathrm{~A} \mathrm{BBr}_{3}$-mediated intramolecular Friedel-Crafts alkylation allows the construction of the tricyclic catechol $( \pm)$-90 from primary alcohol 89, which is then subjected to oxidation with $\mathrm{Ag}_{2} \mathrm{O}$ to complete the formation of $( \pm)$-88. A series of chiral Brønsted and Lewis acidic conditions have also been tested, however, no enantioselection was observed in the cyclization step (Scheme 23).

\section{4 "Aliphatic Friedel-Crafts" reaction}

Towards the synthesis of lycodine, a complanadine alkaloid able to induce the secretion of neurotrophic factors, Lewis has demonstrated the viability of an "aliphatic Friedel-Crafts" approach by achieving the synthesis of the simplified racemic analogue $( \pm)-91 .^{51-53}$ This compound $( \pm)-91$ is accessible from unfunctionalized decalin 92 through reaction with aluminium chloride and acetyl chloride giving trans-decalin ( \pm -93. ${ }^{54}$ Treatment of $( \pm)$-93 with aqueous acid establishes an equilibrium with hydroxyketone $( \pm)-\mathbf{9 4}$, which may be isolated by crystallization. This "aliphatic Friedel-Crafts" reaction is of high relevance in the context of $\mathrm{C}-\mathrm{H}$ activation. Mechanistically, the acylating agent acts as a hydride trap, leading to the formation of the tertiary cation I. Loss of a proton affords the unsaturated decalin II. A second equivalent of acylating agent reacts with II to give cation III. A [1,2]-hydride shift and attack of the oxygen at the position $\alpha$ - to the ring junction then occurs to afford IV. Finally, on work up, loss of a proton affords enol ether $( \pm)$-93 (Scheme 24).

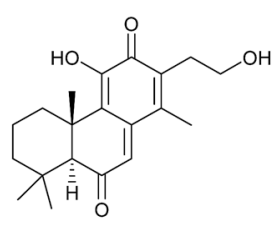

88

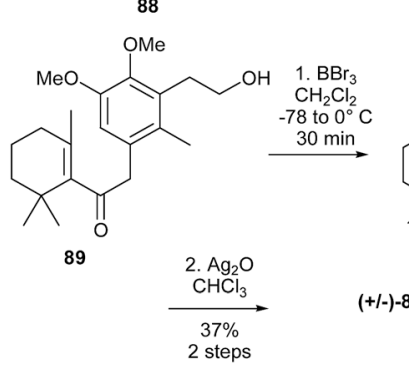

Scheme 23 Yang's total synthesis of an o-hydroxy-p-quinone methide diterpenoid structurally related to taxodione.

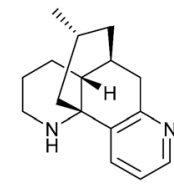

Lycodine

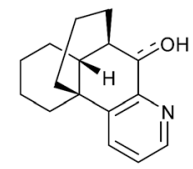

Simplified analogue $(+/-)-91$

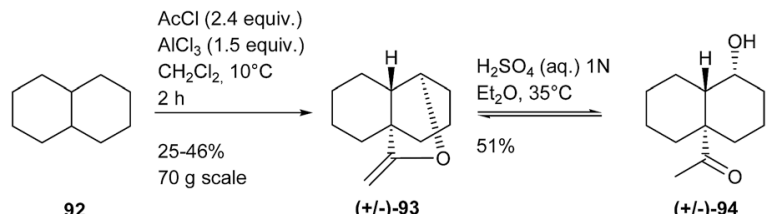

92
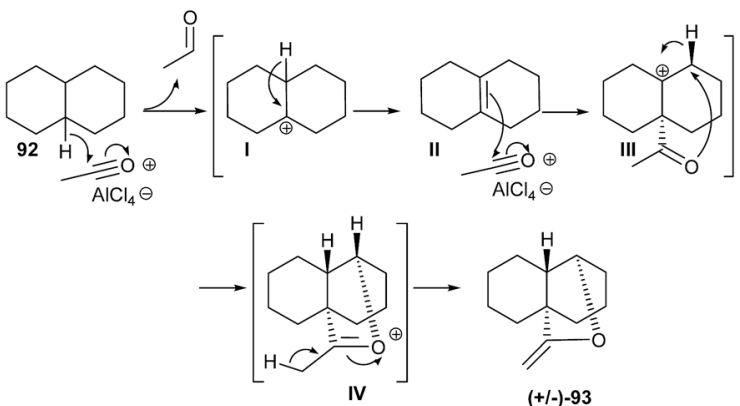

$(+/-)-93$
Scheme 24 Lewis' "aliphatic Friedel-Crafts" approach.

\subsection{Cationic reaction and/or aldehyde-ene reaction}

Cafestol, an ent-kaurene diterpenoid derivative isolated from unfiltered coffee drinks, has recently been discovered to induce apoptosis through regulation of specific protein 1 expression (Sp 1). A bio-inspired synthesis of $( \pm)$-cafestol has been described by Hong in 2014, featuring a $\mathrm{Et}_{2} \mathrm{AlCl}$-promoted aldehyde-ene cyclization and subsequent Friedel-Crafts reaction. ${ }^{55}$

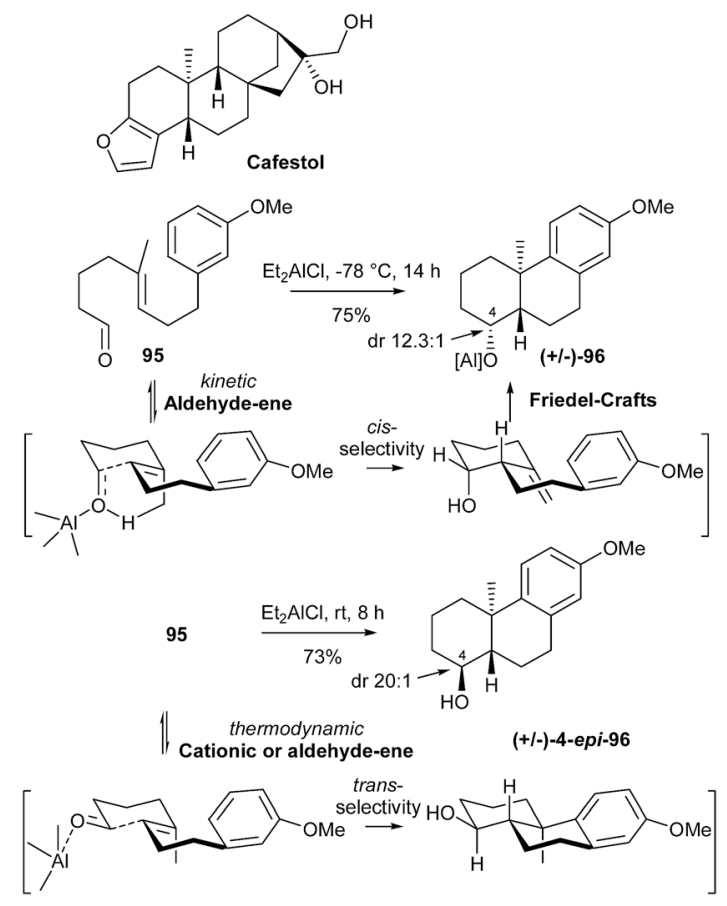

Scheme 25 Hong's total synthesis of $( \pm)$-cafestol. 
Practically, from aldehyde 95, the sequence delivers the tricyclic system ( \pm )-96 in gram scale with high stereo- and regioselectivity (Scheme 25).

It is interesting to note that the stereoselectivity can be switched to $( \pm)-\mathbf{4}-\boldsymbol{e p i}$-96 (isolated in $73 \%$ yield) when the reaction temperature is raised to room temperature. This thermodynamically favorable diastereomer $( \pm)$-4-epi-96 may be derived from a cationic process or an ene cyclization through a boat-like conformation.

\section{Nucleophilic and anionic cyclization}

\subsection{Wieland-Miescher ketones}

Among the various strategies developed for the synthesis of the decalin framework, Robinson annulation is one of the earliest and most widely used. In this context, the Wieland-Miescher ketone is a versatile building block and is still extensively employed.

Toward the total synthesis of rhodexin A, Jung has recently reported the preparation of the optically pure WielandMiescher ketone 98. ${ }^{56}$ Asymmetric elaboration of 98 is carried out through an organo-catalyzed intramolecular aldol reaction of the prochiral triketone $\mathbf{9 7}$ using $(S)-(-)$-proline catalytically as previously described by Buchschacher, Fürst and Gutzwiller (Scheme 26). ${ }^{57}$ After regioselective protection (99), catalytic hydrogenation gives a 10:1 mixture of chromatographically separable diastereomers in which the expected cis-decalin predominates. Subsequent dissolving metal reduction provides, after hydrolysis, the expected alcohol 100. Transformation into vinyl triflate 101, Stille coupling and oxidation finally afford the dienone 102 required to complete the synthesis.
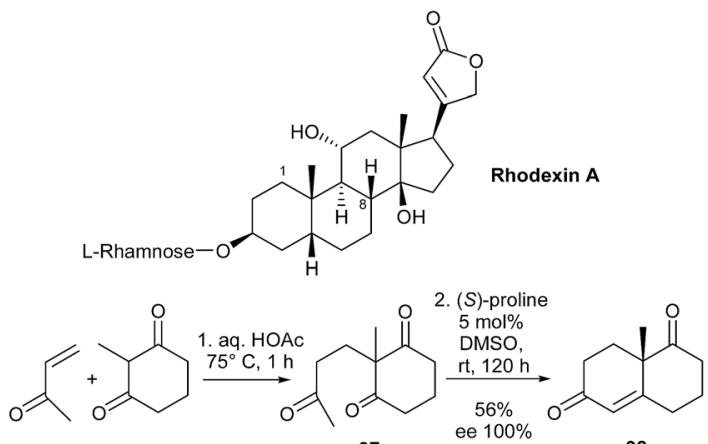

97

98

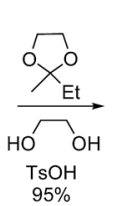

1. $\mathrm{H}_{2}, \mathrm{Pd} / \mathrm{C}$

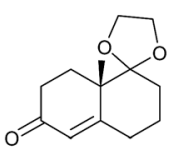

2. $\mathrm{Li} / \mathrm{NH}_{3}$

1. TBSOTF
$\mathrm{Et}_{3} \mathrm{~N},-78^{\circ} \mathrm{C}$
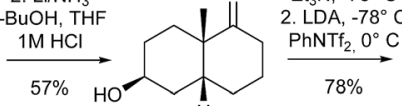

$95 \%$

99

100
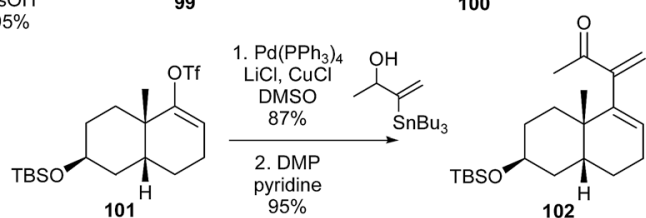

Scheme 26 Jung's Wieland-Miescher ketone strategy towards rhodexin.
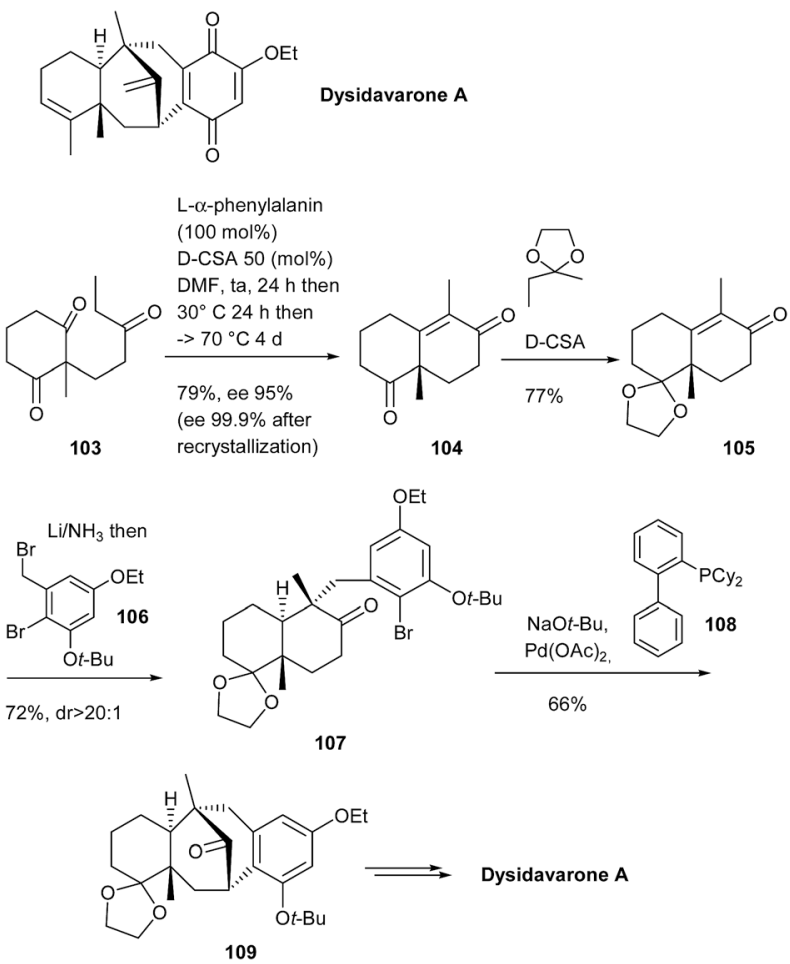

Scheme 27 Menche's total synthesis of dysidavarone A.

A concise total synthesis of dysidavarone A, an antiproliferative marine metabolite with inhibitory activities against protein tyrosine phosphatase 1B (PTP1B) has been achieved by Menche. ${ }^{58}$ The strategy involves the intramolecular $\alpha$-arylation of the Wieland-Miescher type ketone 105. This ketone is prepared in two steps under enantiopure form, from triketone 103 via 104, according to a previously reported procedure involving a $\mathrm{L}$ - $\alpha$-phenylalanin-catalyzed aldol condensation. ${ }^{59}$ The stereoselective coupling of the two building blocks 105 and 106 by a reductive alkylation furnishes the desired diastereomer $\mathbf{1 0 7}$ in 72\% yield with high selectivity. Finally, combination of $\mathrm{Pd}(\mathrm{OAc})_{2}$ with ligand 108 allows the pivotal intramolecular $\alpha$-arylation of ketone 107 , thus affording the desired eight-membered ring compound 109 in $66 \%$ yield (Scheme 27).

Many fungi produce specially adapted-structures called sclerotia that are critical to the long-term survival and propagation of the species. Bradshaw and Bonjoch have reported the total synthesis of $(-)$-anominine, a diterpenoid sclerotia characterized by two quaternary carbons at the decalin ring junction via the cisdecalin 113. ${ }^{60}$ The synthetic route starts with the generation of the Wieland-Miescher ketone type compound 112 through asymmetric Robinson annulation of dione $\mathbf{1 1 0}$ with methyl vinylketone to install the first quaternary center. Using $N$-Ts- $\left(\mathrm{S}_{\mathrm{a}}\right)$ binam-l-Pro $\mathbf{1 1 1}$ as the catalyst, $\mathbf{1 1 2}$ is prepared under highly enantioenriched form ( $94 \%$ ee). The second quaternary center is set-up by a subsequent conjugated addition (Scheme 28).

A concise and stereoselective route to the bridged tricyclic core $( \pm)-\mathbf{1 1 4}$ of racemic platencin, involving the preparation of trans- and cis-decalones $( \pm)-\mathbf{1 1 9}$ and $( \pm)-\mathbf{1 2 0}$, has been reported 


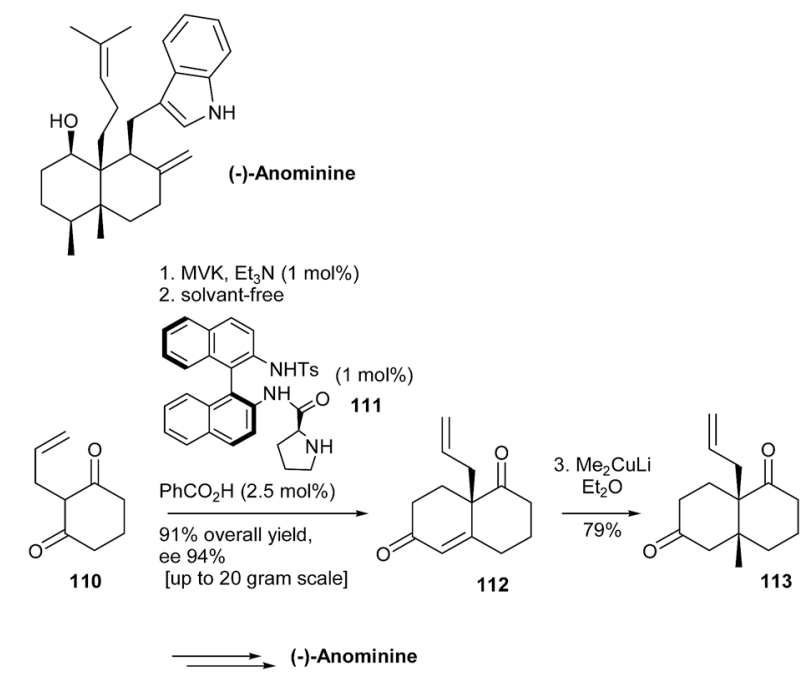

Scheme 28 Bradshaw and Bonjoch total synthesis of (-)-anominine.

by Yadav. ${ }^{61}$ The synthesis begins with an optimized Robinson annulation reaction of ketone $\mathbf{1 1 5}$ with methyl vinylketone to provide the tricyclic enone $( \pm)-\mathbf{1 1 6}$ in $\mathbf{9 0 \%}$ yield. The set-up of the allyl group is then achieved by means of a two-step procedure involving a 1,2-addition followed by an anionic oxy-Cope rearrangement (different attempts to a direct 1,4-addition were not successful). Thus, the enone $( \pm)-\mathbf{1 1 6}$ is subjected to a Grignard reaction with allylmagnesium chloride to provide a separable mixture of diastereomers $( \pm)-\mathbf{1 1 7}$ and $( \pm)-\mathbf{1 1 8}$ in $96 \%$ overall yield. Each diastereomer is further treated with $\mathrm{KH}$ and 18-Crown-6 to provide angular allyl compounds corresponding to trans-fused and cis-fused decalones $( \pm)-\mathbf{1 1 9}$ and ( \pm )-120. Remarkably, both decalones could be converted into the tetracyclic ketone $( \pm)-\mathbf{1 2 1}$ precursor of the target exo-methylene ketone $( \pm$ )-114 (Scheme 29).

\subsection{Michael and/or aldol reaction sequences}

Nicolaou has recently described the total synthesis of potent cytotoxic polyketides myceliothermophins E, C, and D through an unusual cascade sequence of reactions to form the transfused decalin system $125 .{ }^{62}$ The convergent synthesis delivers all three natural products through late-stage divergence. Epoxide $\mathbf{1 2 3}$, readily prepared from citronellal derivative $\mathbf{1 2 2}$, is transformed into ketoaldehyde $\mathbf{1 2 4}$ under catalytic $\mathrm{InCl}_{3}$ conditions. The intended cascade bis(cyclization), intramolecular Michael addition followed by aldol condensation, is found to proceed in 92\% yield ( $3: 1 \mathrm{dr})$, in the presence of catalytic amounts of PTSA in refluxing benzene. The direct conversion of epoxide 123 to decalin $\mathbf{1 2 5}$ is also achieved under the same conditions, albeit in only $65 \%$ yield ( $3: 1 \mathrm{dr}$ ). This enone decalin system 125 is then functionalized to provide the aldehyde intermediate $\mathbf{1 2 6}$ within 15 steps. Final attachment of the pyrrolidinone structural motif to $\mathbf{1 2 6}$ allows the elaboration of the targeted myceliothermophins (Scheme 30).

It seems interesting to mention a reference reported by Chen regarding an unprecedented organocatalytic reaction of $\gamma$ -
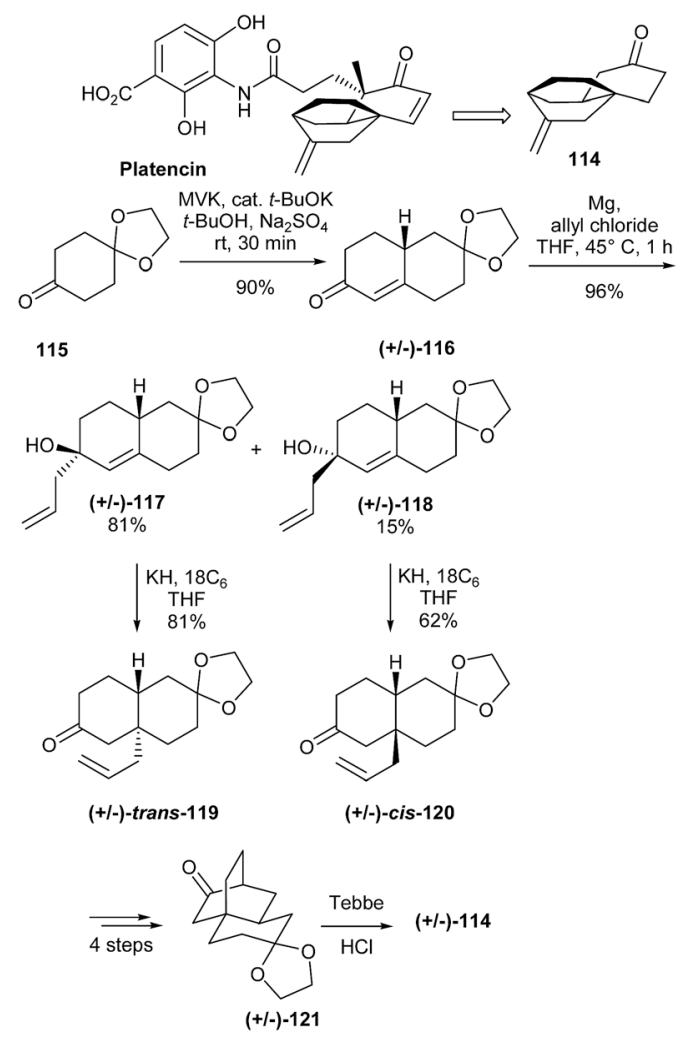

Scheme 29 Yadav's total synthesis of the bridged tricyclic core of racemic platencin.

nitroketones 127 with $\alpha, \beta$-unsaturated aldehydes 128. The method offers a straightforward access to polyfunctionalized [4.4.0] bicyclic skeletons 130. ${ }^{63}$ These hexa-substituted decalin carboxaldehydes $\mathbf{1 3 0}$ are obtained by a diphenylprolinol silyl ether 129 mediated nitro-Michael/aldol reaction, with excellent diastereo- and enantioselectivity (up to $>99 \%$ de and ee) via enamine intermediate I. On a mechanistic point of view, the intramolecular reaction proceeds through attack on the $R e$ face of the ketone to form the decalin system. Noteworthy, starting $\gamma$-nitroketones 127 can be prepared through an organocatalytic Michael addition in high yield and selectivity (Scheme 31).

The one-pot process described by Gaunt, involving oxidative dearomatization of substituted phenols followed by a desymmetrizing secondary amine catalyzed asymmetric intramolecular Michael addition, allows the formation of a range of highly functionalized [4.4.0] systems with excellent selectivity. ${ }^{64}$ Thus, the decalin $\mathbf{1 3 4}$ can be generated in $\mathrm{MeOH}$ acting as solvent and nucleophile, through oxidation of phenol 131 using hypervalent iodine and subsequent desymmetrization of mesocyclohexadienone intermediate $\mathbf{1 3 2}$ by means of the sterically bulky catalyst 133 (Scheme 32). The reaction proceeds with a high yield $(75 \%)$ and selectivity ( $>20: 1 \mathrm{dr}$ and $99 \%$ ee).

An anionic oxy-Cope/transannular Michael addition approach to potent antimalarial 7,20-di-iso-cyanoadocianes has been investigated by Vanderwal. ${ }^{65}$ Deprotonation of spirocycle $( \pm)$-135 initiates an efficient sigmatropic rearrangement and further deprotection with TBAF affords the desired cyclodecenone $( \pm)$-136 in 77\% over two steps. Exposure of $( \pm)$-136 to 

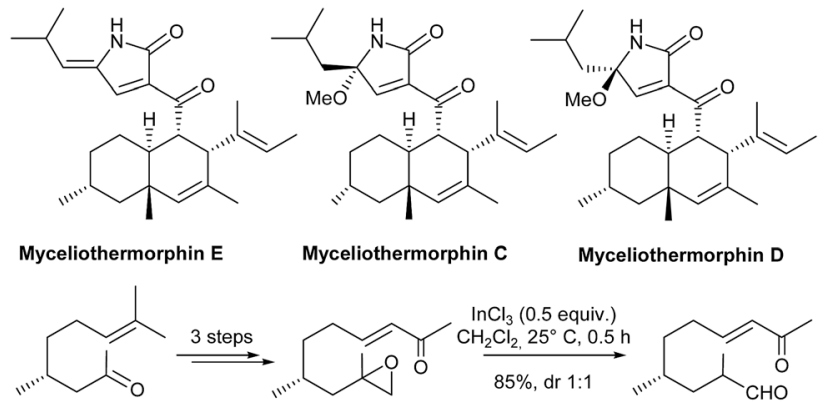

122

123

124
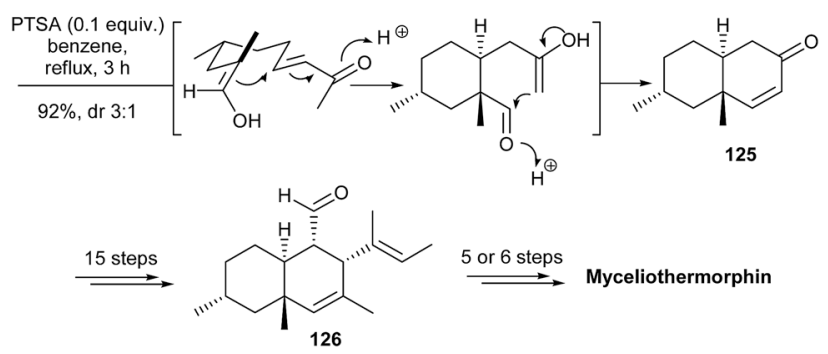

Scheme 30 Nicolaou's total synthesis of myceliothermophins.

basic methanol results in a kinetic transannular conjugate addition to give diastereomers $( \pm)$-137 and $( \pm)$-138, both bearing a cis ring fusion (Scheme 33). ${ }^{66}$

Angular 6-6-6 tricyclic systems are frequently encountered in polycyclic terpenoids and other natural products. While a number of strategies exist to synthesize such motifs, the transannular Michael reaction cascade proved to be particularly effective. Evans reported the first synthesis of salvinorin A, a potent $\kappa$ opioid receptor agonist, through an elegant transannular reaction cascade of the bisenone macrocycle 139; the desired tricyclic product $\mathbf{1 4 0}$ is isolated as a single diastereomer in $99 \%$ yield ${ }^{67}$ Practically, TBAF initiates this reaction involving the simultaneous creation of two bonds, two rings and three consecutive stereocenters (including two quaternary ones). The elaboration of $\mathbf{1 4 0}$ is consistent with a transannular Michael reaction cascade via the all chair-like transition state I (Scheme 34). However, a concerted mechanism involving exo-selective Diels-Alder cycloaddition (transition state II) cannot be excluded, since both mechanistic pathways lead to the same product.

More recently, Yang has described the elaboration of the ABC carbocyclic core of norzoanthamine, a marine alkaloid with a potent antiosteoporotic effect, by a similar highly stereoselective transannular Michael reaction cascade from the 14membered macrocyclic lactone $141{ }^{68}$ The tetracyclic product 142 is isolated in $87 \%$ yield as the sole product. However, as previously observed, this result does not permit to rule out the possibility of a transannular Diels-Alder reaction pathway (Scheme 35). ${ }^{69}$

Many routes have been designed towards platencin and derivatives. They frequently involve the construction of a key enone precursor, first described by Nicolaou ("Nicolaou's intermediate"). ${ }^{24}$ Intramolecular aldol reaction has proved to be a powerful tool for the elaboration of this late intermediate. ${ }^{70-72}$

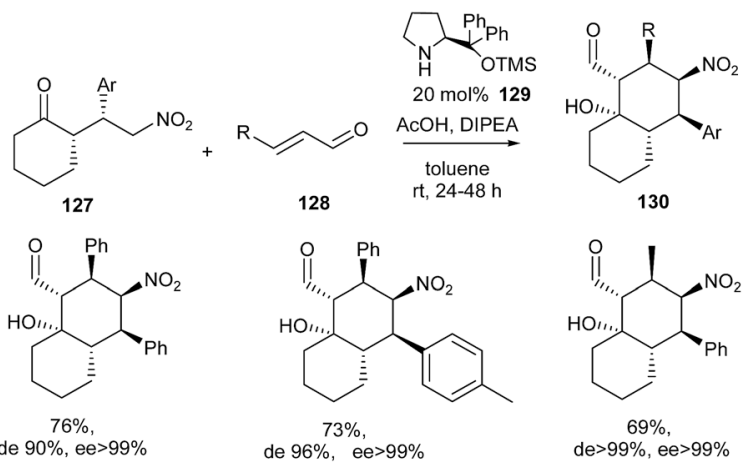

de $90 \%$, ee $>99 \%$

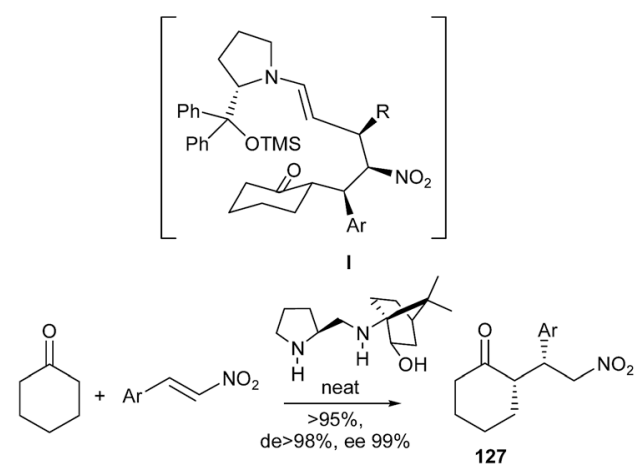

de $>99 \%$, ee $>99 \%$

Scheme 31 Chen's organocatalytic reaction of $\gamma$-nitroketones with $\alpha, \beta$-unsaturated aldehydes.

Accordingly, from aldehyde 143, the cyclization is efficiently carried out under basic conditions in $99 \%$ yield. Interestingly, the precursor 146 is obtained by Nicolaou through an asymmetric intermolecular Diels-Alder reaction (144) followed by a radical rearrangement $(\mathbf{1 4 5} \rightarrow \mathbf{1 4 6})$ (Scheme 36$)$.

Total synthesis of racemic omphadiol and pyxidatol $\mathrm{C}$, two isomeric africanane sesquiterpenes sharing identical 5-7-3 tricyclic carbon skeleton, has been achieved by Liang. ${ }^{73}$ The formation of the cis-fused 5-7-carbocyclic common intermediate $( \pm)-\mathbf{1 5 0}$ is realized by a Tiffeneau-Demjanov rearrangement from trans-decalin $( \pm)$-149. The synthesis starts with an aldolHenry cascade and subsequent Parikh-Doering oxidation which allow isolation of the desired decalin precursor $( \pm)$-148 in $45 \%$ yield from ketone 147. After conversion into the corresponding

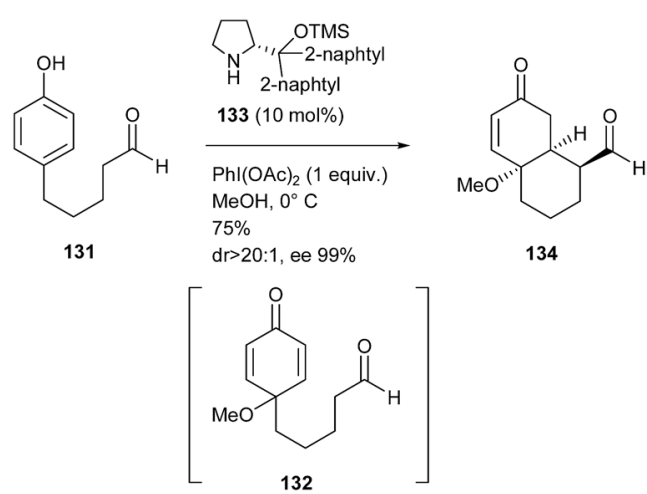

Scheme 32 Gaunt's one-pot oxidative dearomatization of phenols and asymmetric intramolecular Michael addition. 


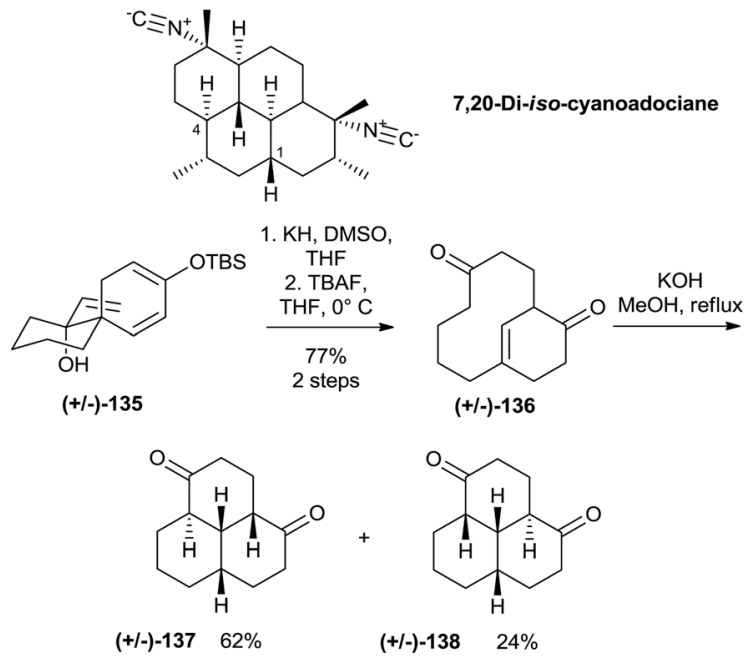

Scheme 33 Vanderwal's approach to 7,20-di-iso-cyanoadociane.

amine $( \pm)-\mathbf{1 4 9}$, Tiffeneau-Demjanov rearrangement generates the desired cis-fused 5-7-carbocycle $( \pm)$-150 in $62 \%$ with complete diastereocontrol (Scheme 37).

A relevant process involving an enantioselective copper(I)catalyzed borylative aldol cyclization of enones has been developed by Lam to deliver decalins containing four contiguous stereocenters, two of them being quaternary. ${ }^{74}$ This domino sequence is based on the trapping of a copper enolate by a pendant ketone. Under optimized conditions (with Josiphos ligand 152 for enantio-induction), a range of decalins 153

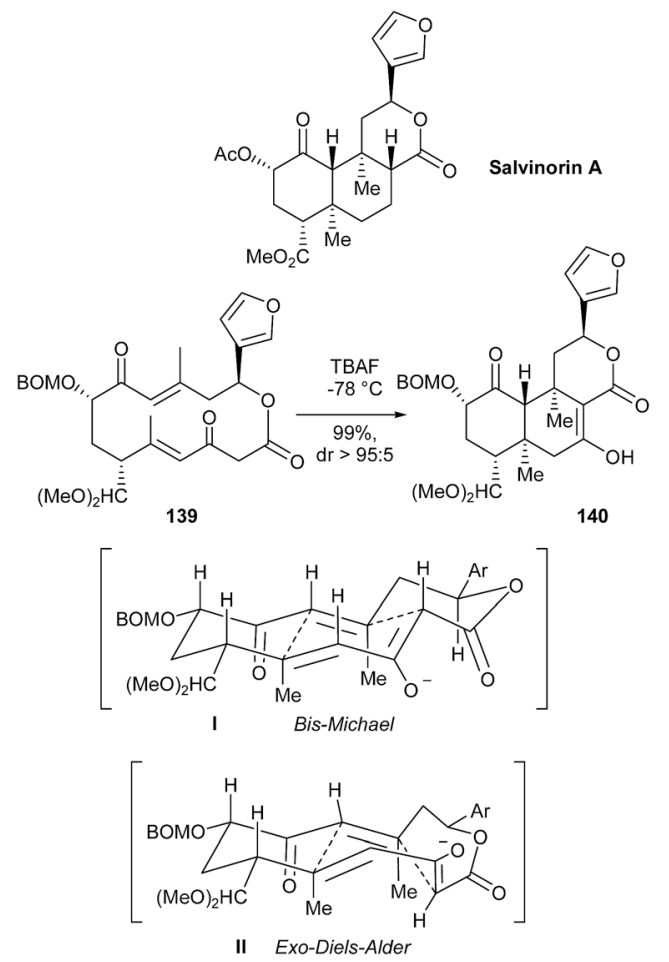

Scheme 34 Evans's synthesis of salvinorin A by transannular Michael reaction cascade.

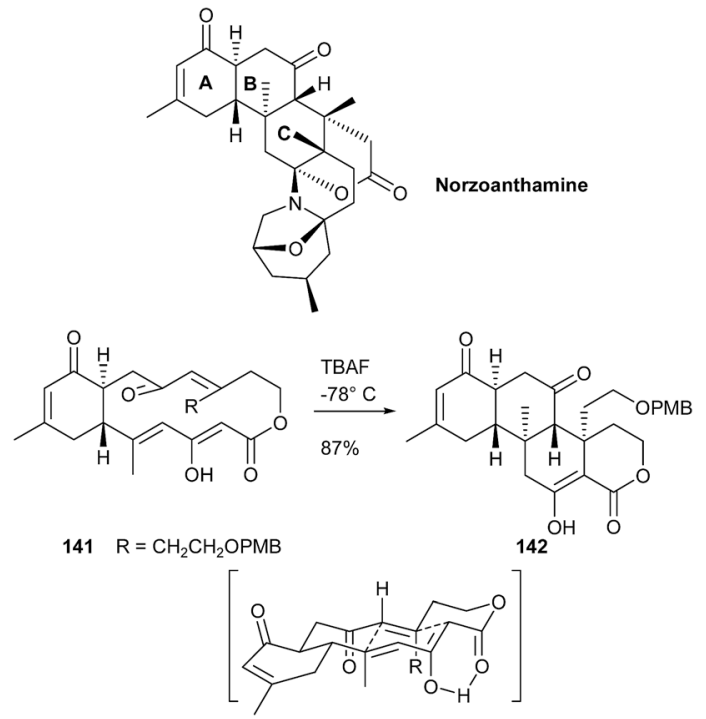

Scheme 35 Yang's synthesis of the ABC carbocyclic core of norzoanthamine by transannular Michael reaction cascade.

can be obtained in high yields and selectivity from enone diones 151. The formation of these products can be explained by aldol cyclization through a $(Z)$ enolate in the chair-like Zimmermann-Traxler type transition state $\mathbf{I}$. To demonstrate the synthetic utility of the bicyclic products, further transformations of $\mathbf{1 5 4}$ have been conducted to yield the corresponding alcohol 155 or the potassium trifluoroborate salt 156 (Scheme 38).

\subsection{Allylation reaction}

The first synthesis of $6^{\prime}$-hydroxyarenarol, the proposed precursor of the natural product popolohuanone $\mathrm{E}$, has been efficiently completed by Anderson. ${ }^{75}$ The cis-decalin 160 has

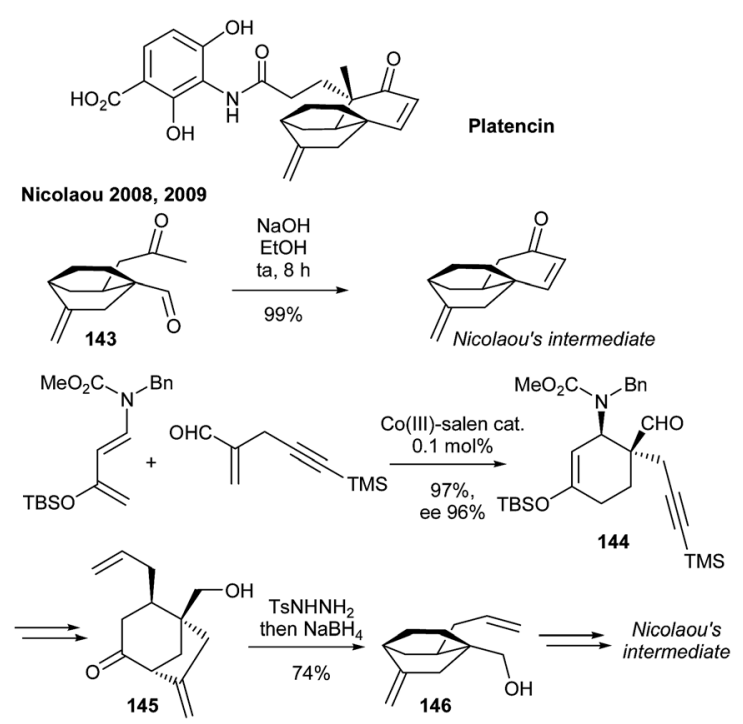

Scheme 36 Nicolaou's synthesis of platencin by intramolecular aldol reaction. 


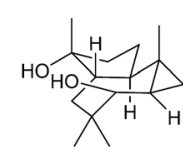

Omphadiol
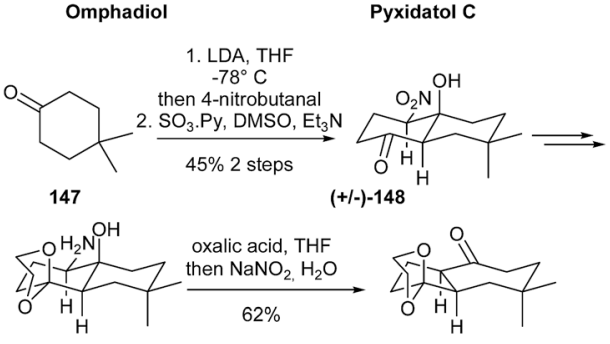

$(+/-)-149$

$(+l-)-150$

Scheme 37 Liang's total synthesis of racemic omphadiol and pyxidatol C.

been prepared by means of an intramolecular Hosomi-Sakurai reaction involving allylsilane 159. Treatment of 159 with titanium tetrachloride in the presence of $\mathrm{MeSCH}_{2} \mathrm{Cl}$ gives the desired decalin 160 in 68\% yield as a single diastereomer, and further reduction of the sulfide provides the product 161. The precursor of Hosomi-Sakurai reaction has been prepared through coupling of vinyl bromide 157 and iodide 158 and subsequent deprotection of the ketal (Scheme 39).

\subsection{Anionic polycyclization reaction ("anionic Diels-Alder reaction")}

An interesting strategy for establishing decalin scaffolds is the "anionic Diels-Alder reaction" developed by Deslongchamps. ${ }^{76-78}$
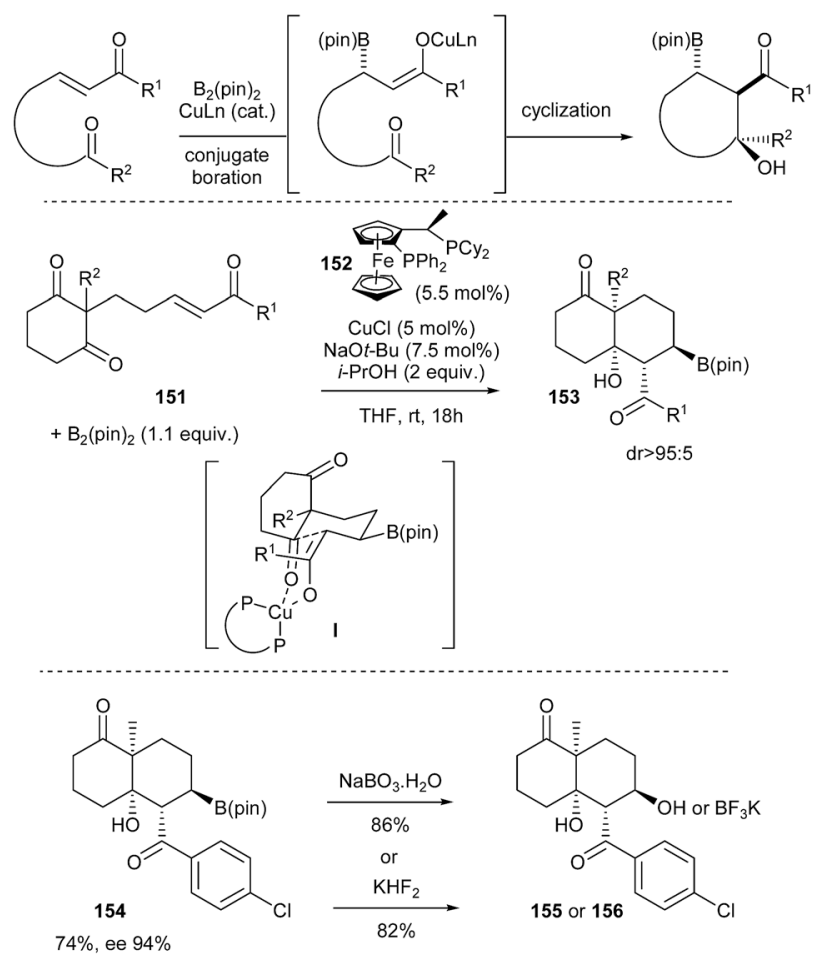

Scheme 38 Lam's borylative aldol cyclization of enones.
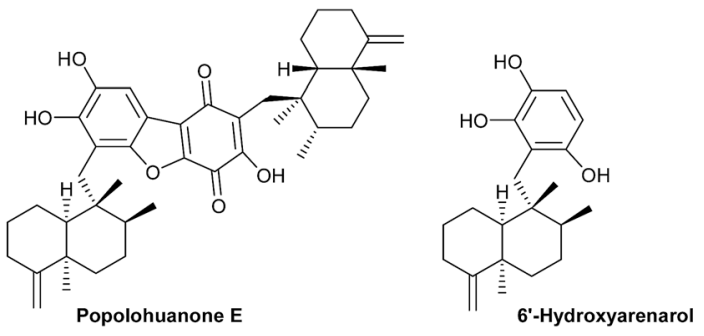

157
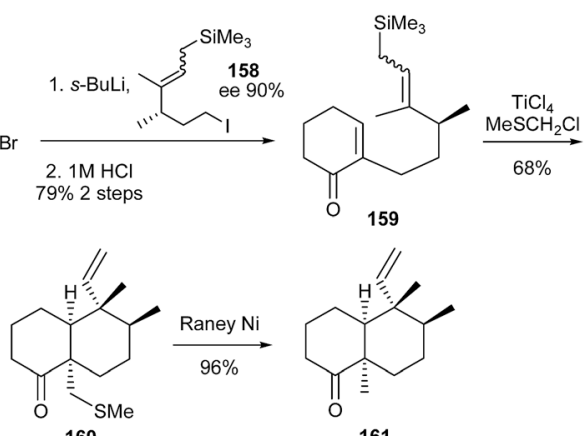

Scheme 39 Anderson's synthesis of 6'-hydroxyarenarol, precursor of popolohuanone E.

The initial "Deslongchamps annulation" consists in the addition of the enolate of enone ester 163 (Nazarov reagent) to activated cyclohexenone 162, to successively afford cis-decalins 164 after cyclization and 165 after decarboxylation. Under similar conditions, the reaction involving the same activated enone $\mathbf{1 6 2}$ and the enolate of enone sulfoxide 166 directly gives the unsaturated decalin 167 with the stereocenter at C9 opposite to that observed in 165. Such annulations are remarkably useful since they are able to create up to four new stereocenters which matches the "stereogenecity" of Diels-Alder reactions. Mechanistically, it has been envisioned that the reaction involving the enolate 168 of enone ester 163 could proceed through a reversible double Michael addition via the exo approach $\mathbf{I}$. However, concerning the enolate
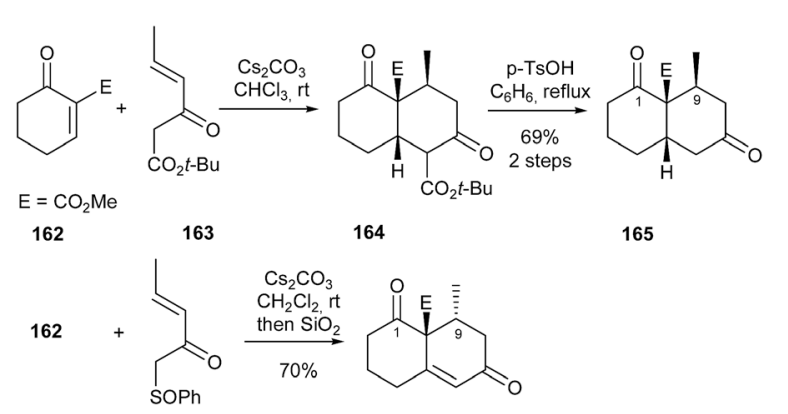

166
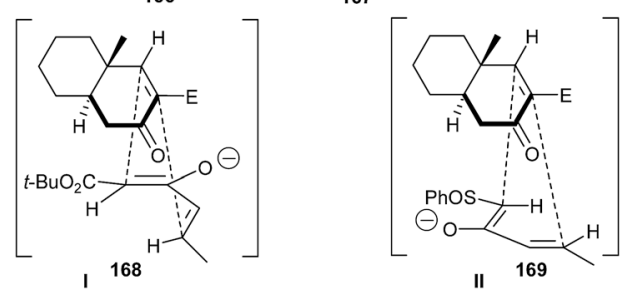

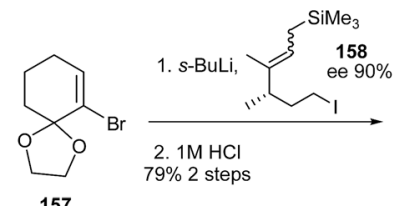

Scheme 40 Deslongchamps' "anionic Diels-Alder reaction". 


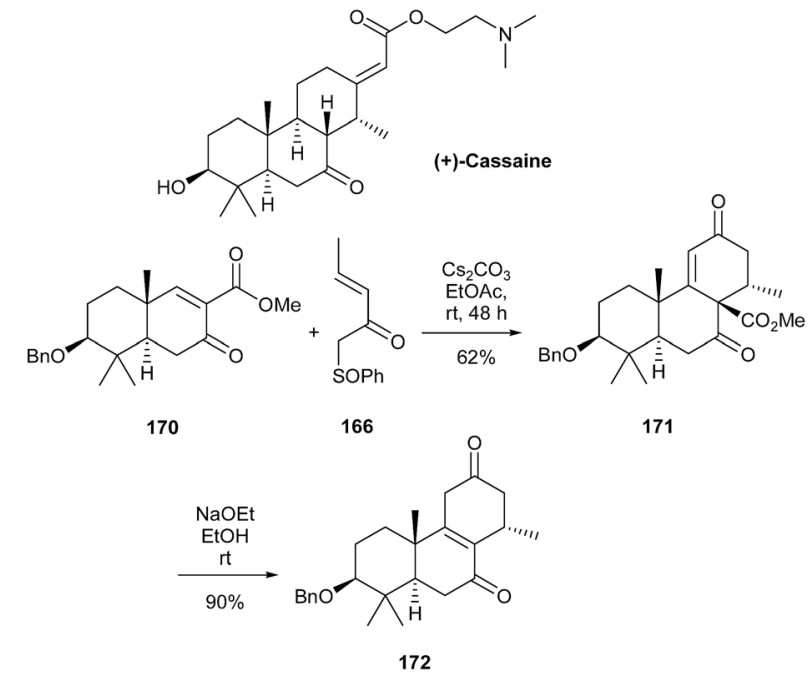

Scheme 41 Deslongchamps' synthesis of (+)-cassaine.

169 of enone sulfoxide 166, a Diels-Alder cycloaddition through the endo transition state II would explain the selectivity (Scheme 40).

Using this strategy, the stereocontrolled synthesis of (+)-cassaine, a nonsteroidal inhibitor of $\mathrm{Na}^{+}-\mathrm{K}^{+}-\mathrm{ATP}^{\text {ase }}$ has been reported. Anionic polycyclization of bicyclic enone $\mathbf{1 7 0}$ and enone sulfoxide 166 in the presence of cesium carbonate furnishes the diastereomerically pure tricycle 171 in $62 \%$ yield. Then, a base induced decarbomethoxylation of 171 with concomitant olefin migration affords enone intermediate $\mathbf{1 7 2}$. Finally, this tricyclic compound $\mathbf{1 7 2}$ is easily converted into the natural product through a sequence of functional group manipulations (Scheme 41).

\section{Radical reactions}

The use of radical reactions to construct decalin systems is currently well-established. Thereby, in many cases, these cyclizations represent a useful complementary approach to conventional biomimetic cationic sequences.

In 2013, Carreira has described the first total synthesis of entcrotogoudin, a recently isolated cytotoxic diterpene. ${ }^{79}$ The synthesis features a key radical cyclopropane-opening/annulation/elimination cascade to diastereoselectively access the tetracyclic carbon skeleton (Scheme 42).

Desymmetrization of meso diketone $\mathbf{1 7 3}$ with Baker's yeast affords endo-alcohol $\mathbf{1 7 4}$ as a single diastereomer and enantiomer. The key cascade transformation of allylic pivaloate $\mathbf{1 7 5}$ into the tetracyclic product $\mathbf{1 7 6}$ promoted by samarium(II) diiodide, proceeds in $80 \%$ yield with a high diastereoselectivity. Mechanistically, the alkene would serve as an acceptor to a reactive nucleophilic species at $\mathrm{C} 10$ derived from reductive opening of the cyclopropane ring $(\mathbf{I} \rightarrow \mathbf{I I})$.

A route to $( \pm)$-platencin has been reported in 2011 by Yoshimitsu, in which a radical carbon-carbon bond forming reaction that involves titanium(III)-mediated cyclization, is implemented. ${ }^{3,25,80}$ Cyclization of epoxide ( $( \pm$ )-177 (d.r. $2: 3$ ) was
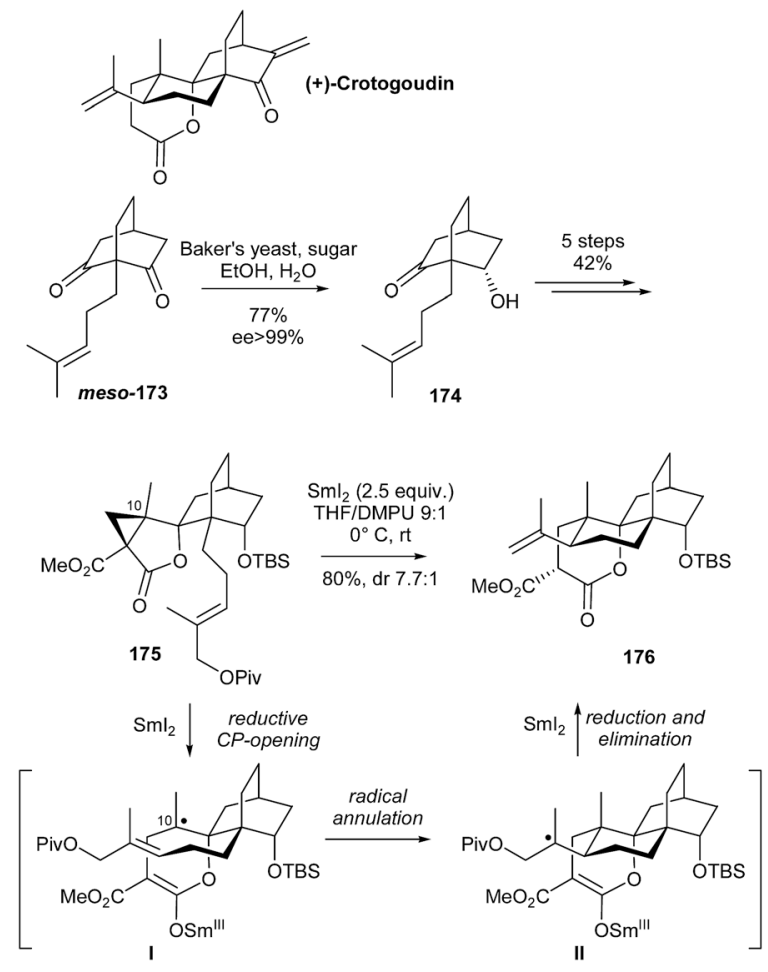

Scheme 42 Carreira's total synthesis of ent-crotogoudin.

found to successfully provide the desired tricyclic compound $( \pm)-\mathbf{1 7 8}$ as a single product in $\mathbf{8 7 \%}$ yield via the thermodynamic radical intermediate $\mathbf{I}$ (Scheme 43 ).

Interestingly, Fernàndez-Mateos has recently developed a short synthesis of the BCDE core of azadiradione, a limonoid with cytotoxic activity. ${ }^{81}$ The key-step relies upon a titanocene(iii)-promoted tandem cyclization of unsaturated epoxy nitrile $( \pm)$-180 that can be readily obtained from $\alpha$-ionone $\mathbf{1 7 9}$. The tandem radical cyclization is carried out by reaction of epoxide $( \pm)-\mathbf{1 8 0}$ with in situ generated titanocene chloride, to provide the hydroxyketone $( \pm)-\mathbf{1 8 1}$ as the sole product in $82 \%$

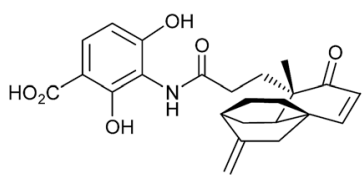

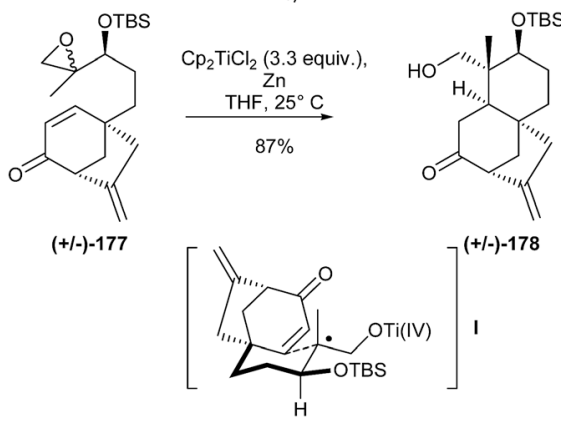

Scheme 43 Yoshimitsu's synthesis of $( \pm)$-platencin. 

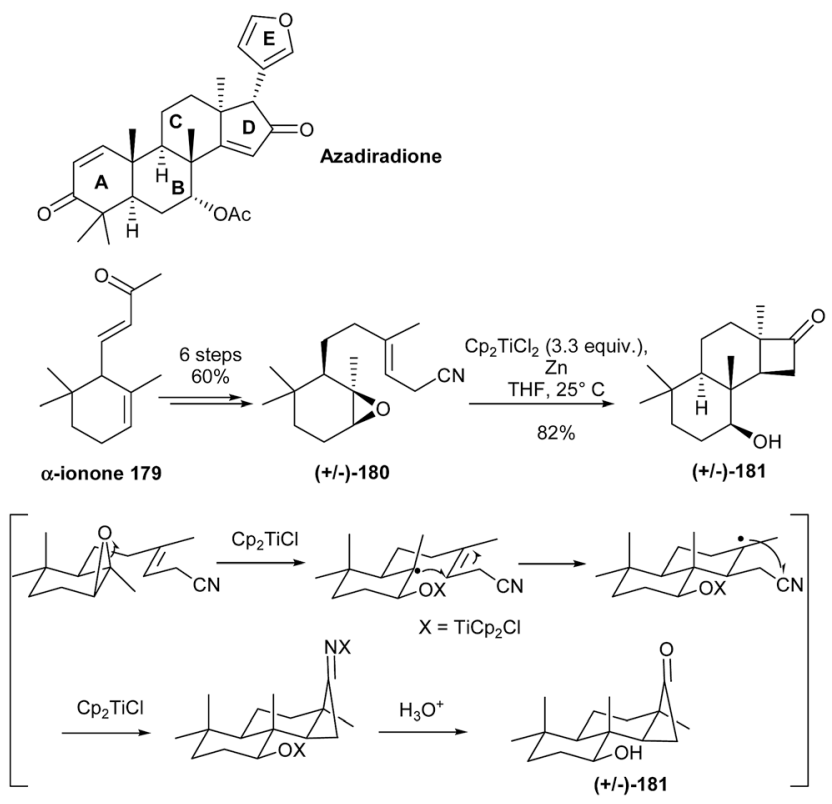

Scheme 44 Fernàndez-Mateos' synthesis of the BCDE core of azadiradione.

yield. The cyclization mechanism successively includes the homolytic cleavage of the oxirane with titanocene chloride, a 6endo cyclization onto the double bond, and finally a 4-exo cyclization on the nitrile group (Scheme 44).

Very recently, Cuerva has reported a bio-inspired Ti(III)catalyzed radical cyclization involving epoxypolyenes containing keto units positioned along the polyene chain. ${ }^{82}$ Noteworthy, the number of rings in the final carbocycle is directly linked to the position of the keto group and does not depend on the number of prenyl subunits in the starting material. Bicyclic products (such as $( \pm$ )-183 and $( \pm$ )-185 respectively obtained from $( \pm)$-182 and $( \pm)$-184) always exhibit a cis-fused decalin system. Tricyclic products (such as $( \pm$ )-188 obtained from $( \pm)-187)$ mainly display a trans fusion between the first two cyclohexanes, and a cis fusion between the second and third cyclohexane rings. These results suggest that the cis stereochemistry is intrinsic to the radical addition reaction in the presence of the keto group. Theoretical calculations have revealed that the presence of the ketone moiety forces the side chain to follow a reaction pathway through the $\beta$ face, promoting the cis chemistry in the final cyclization reaction. It has been evidenced that, during the bicyclization process, the favored sequence is the formation of the radical species II from endo-I. Furthermore, bicyclic system $( \pm)$-185 can be easily converted into the cis-terpenic structure $( \pm)-\mathbf{1 8 6}$, structurally related to existing natural labdanes (Scheme 45).

Towards the elaboration of rosthorin, an ent-kaurane diterpenoid, a general two-phase strategy has been considered by Baran. ${ }^{83}$ More precisely, the approach consists first in a cyclase phase, where a low oxidized terpene skeleton is rapidly constructed, then in an oxidase phase, where a series of siteselective oxidations furnishes the expected natural product. Analysis of rosthorin through this two-phase sequence leads to
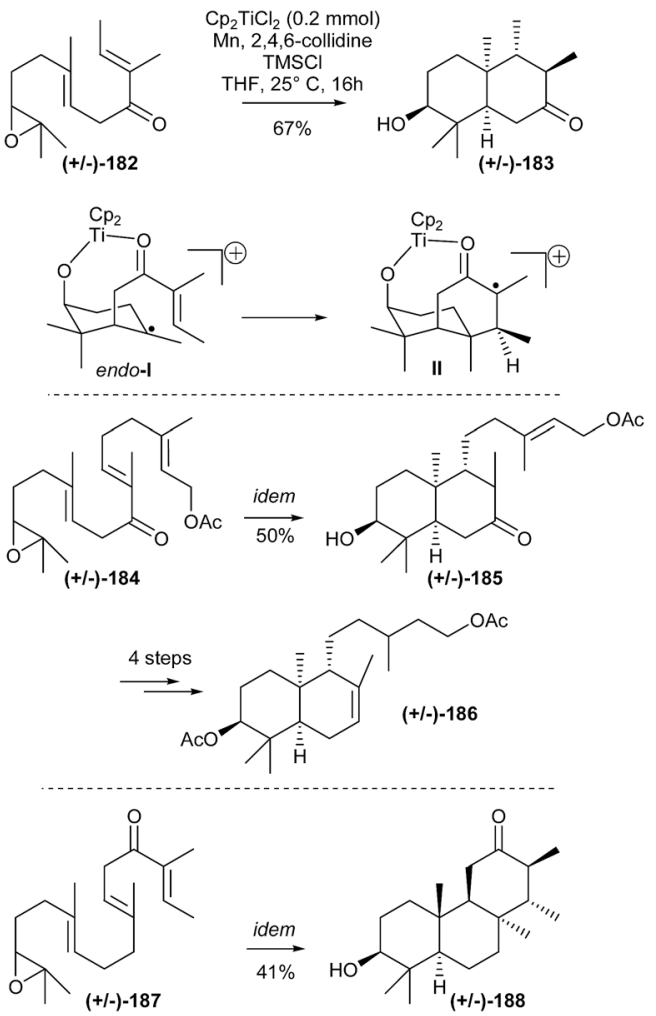

Scheme 45 Cuerva's Ti(III)-catalyzed radical cyclization of epoxypolyenes with keto units.

the tetracyclic compound $\mathbf{1 8 9}$ as a cyclase-phase end. For the elaboration of $\mathbf{1 8 9}$ from enone 190, a polarity reversal sequence allowing the direct addition of an olefin to an enone has been investigated. To this aim, a redox method that utilizes an iron catalyst and a silane reducing agent has been set-up. For instance, when cyclohexenone $( \pm)-191$ is subjected to $\mathrm{Fe}(\mathrm{acac})_{3}$ and $\mathrm{PhSiH}_{3}$ conditions, the cis-decalin $( \pm)$-192 is obtained in $60 \%$ yield. The mechanism, proposed for this reductive olefin coupling reaction, is as follow: donor olefin would abstract a hydrogen radical from Fe hydride $\mathrm{LnFe}^{\mathrm{III}}-\mathrm{H}$ derived from $\mathrm{Fe}(\mathrm{III})$
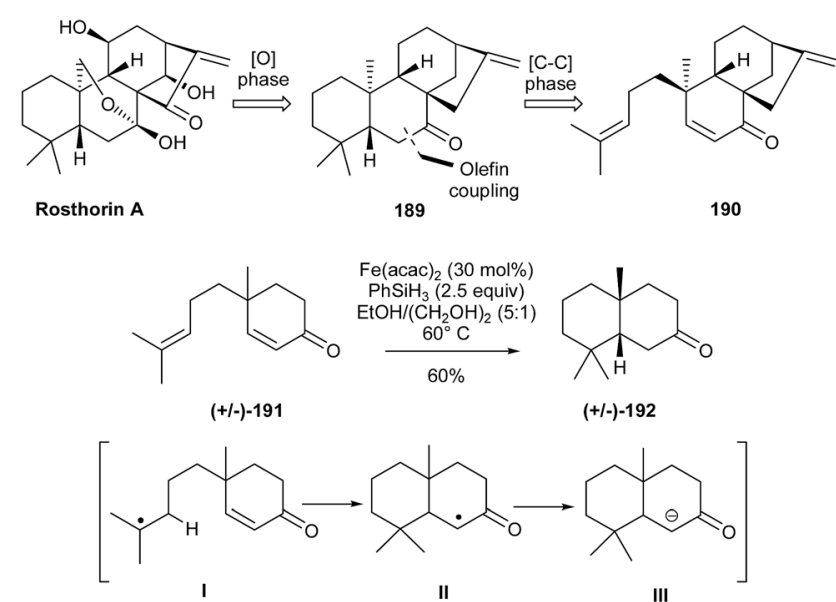

Scheme 46 Baran's general two-phase strategy for elaboration of rosthorin. 
species and $\mathrm{PhSiH}_{3}$, to generate tertiary radical $\mathbf{I}$ and $\mathrm{LnFe}^{\mathrm{II}}$. Then, Michael conjugate addition (II) followed by single-electron transfer (from $\mathrm{LnFe}^{\mathrm{II}}$ ), would provide intermediate III (Scheme 46).

An expeditious method has been developed by Hong for the enantioselective synthesis of highly functionalized decalin systems 196 containing seven contiguous stereogenic centers with high enantioselectivities $(>99 \%){ }^{84}$ The one-pot methodology combines an organocatalytic cascade double Michael addition and a visible light driven photocatalytic Michael-aldol reaction involving three components: bromoenal 193 and both $\alpha, \beta$-unsaturated aldehydes, cinnamaldehyde 194 and methacrylaldehyde 195 to give a mixture of decalins 196 and 197, 196 being the major isomer. To account for the stereoselectivity of the transformation, a mechanism is proposed. Initially, stereoselective nucleophilic attack of the iminium derived from bromoenal 193 and organocatalyst 129, on the Re face of activated cinnamaldehyde 194, followed by Michael reaction, affords the tetrasubstituted cyclohexane 198. Then, under photoredox conditions, $\mathrm{Ru}(\mathrm{bpy})_{3}{ }^{+}$generated from $\mathrm{Ru}(\mathrm{bpy})_{3}{ }^{2+}$ donates an electron to bromide 198, thereby engendering the ester radical I. Conjugate addition of this alkyl radical $\mathbf{I}$ to methacrylaldehyde 199 followed by aldol cyclization affords the decalin adduct $\mathbf{2 0 0}$ as the major isomer, through the transition state TS II. Computational investigations on the origin of the stereoselectivity of the 6-exo-trig radical cyclization has revealed that TS II, where the sterically demanding phenyl group of cyclohexane and the methyl group of methacrylaldehyde adopt equatorial orientations, is the lowest-energy transition state (Scheme 47).

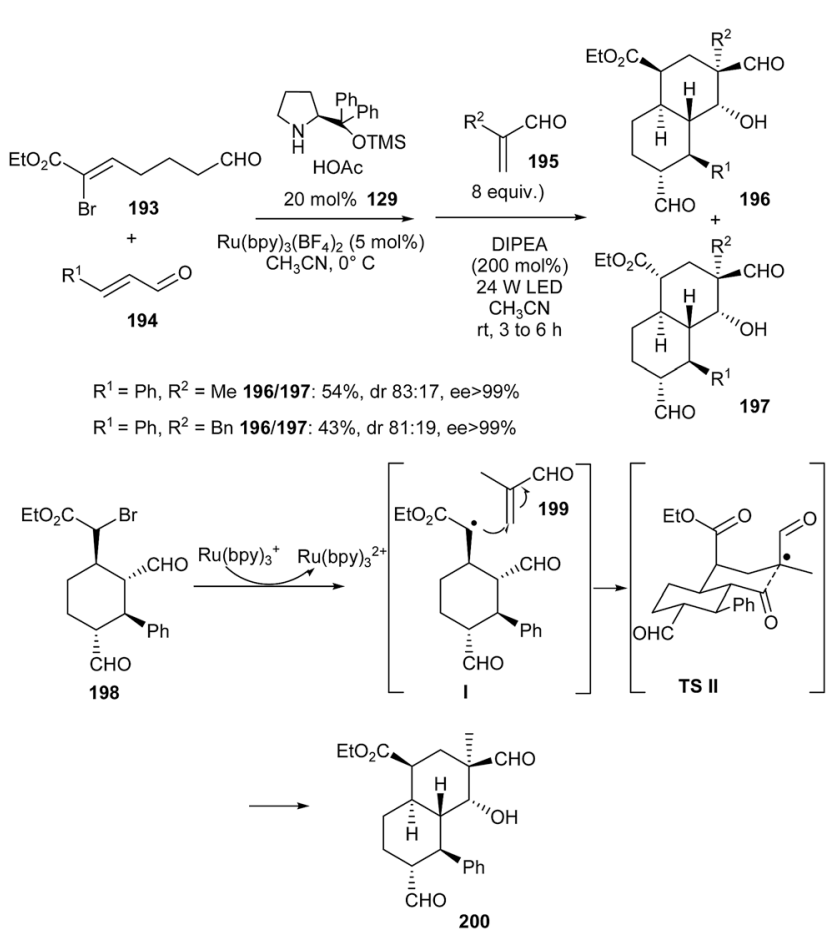

Scheme 47 Hong's strategy for the enantioselective synthesis of highly functionalized decalins.

\section{Miscellaneous pericyclic reactions (except Diels-Alder reactions)}

The first total synthesis of (-)-teucvidin, a 19-nor-clerodane bearing a $\gamma$-lactone moiety fused into the decalin core has been reported by Lee. ${ }^{85}$ The synthetic strategy involves a one pot diastereoselective Michael/Conia-ene cascade cyclization reaction, which permits a rapid and stereoselective elaboration of the cis-decalin skeleton by substrate control. Michael addition of the enamine derivative of acyclic aldehyde 201 (1: 1 mixture of $(Z) /(E)$ stereomers) smoothly proceeds to give the kinetic Michael adduct intermediate 202. After subsequent addition of In $(\mathrm{OTf})_{3}$ and $4 \breve{A}$ molecular sieves, a Conia-ene reaction allows for the construction of the second cycle of the decalin core. The cis-decalin 203, comporting the required functionalities and stereogenic centers for the synthesis of the target molecule, is then isolated in $72 \%$ yield as a single isomer. Based on the stereochemistry of decalin 203 and on the systematic $(Z) /(E)$ equilibration of starting material 201, Lee proposes that $(Z)-201$ would be first equilibrated to $(E)$-201 under the reaction conditions then the Michael reaction of $(E)$-201 could lead to 202 via the twist-chair-like transition state $\mathbf{I}$. Thereafter, highly functionalized cis-decalin 203 permits a straighforward access to (-)-teucvidin (Scheme 48).

Williams has described the stereocontrolled synthesis of the cis-hydroxydecalin system $( \pm)$-204 of crotonins, a rare group of 19-nor-clerodanes. ${ }^{86}$ The key step relies on a thermal $6 \pi$-electrocyclization/hetero-Diels-Alder sequence from triene 205 .
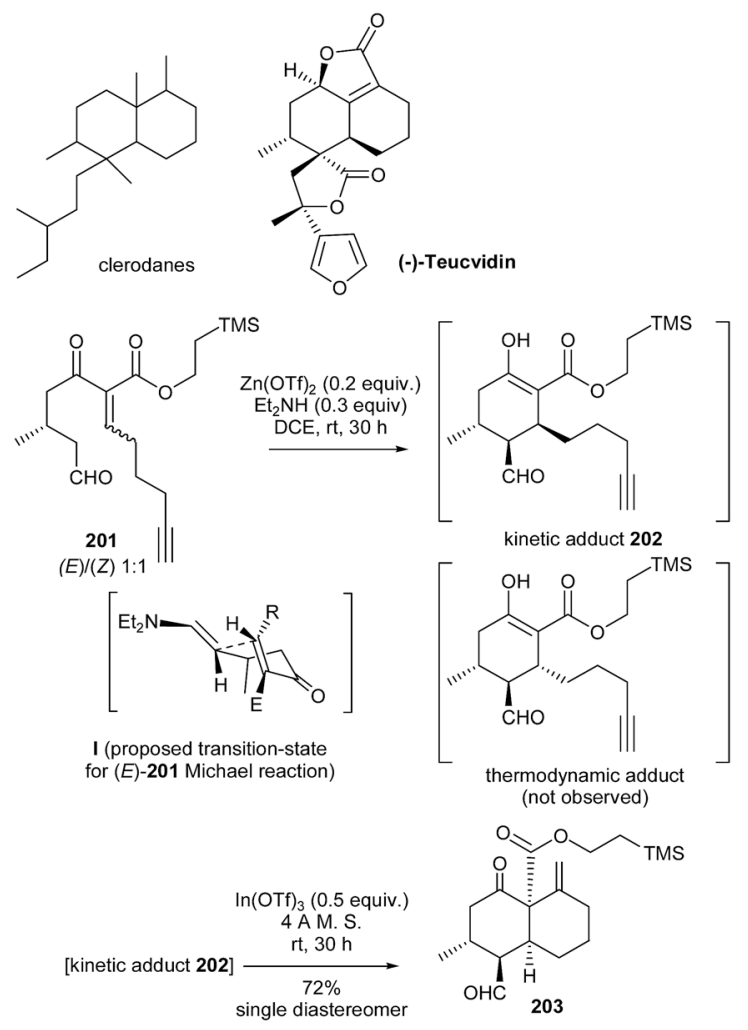

Scheme 48 Lee's total synthesis of (-)-teucvidin. 


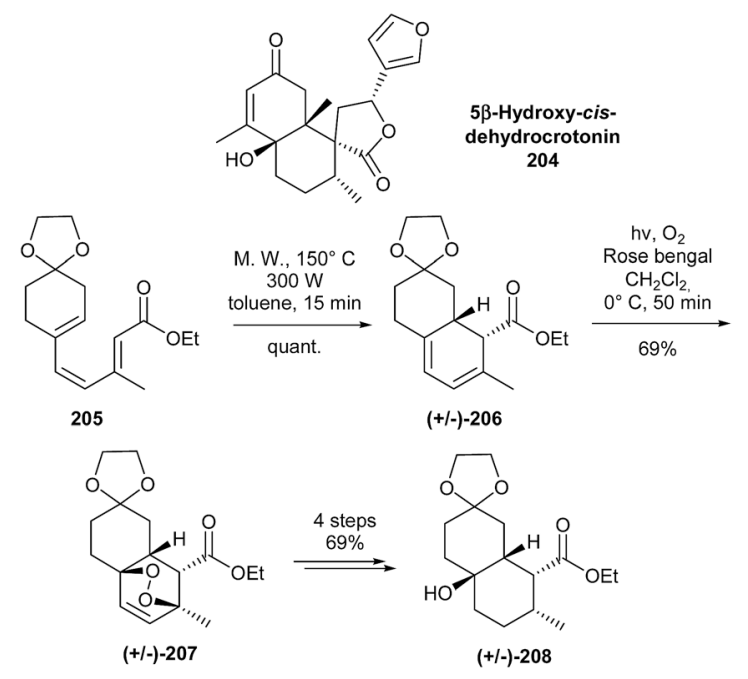

Scheme 49 Williams' synthesis of the cis-hydroxydecalin system of crotonin.

Under microwave irradiation, the electrocyclization reaction provides diene $( \pm)$-206 in quantitative yield as a single diastereomer. Subsequent installation of the hydroxy function is achieved through a hetero $[4+2]$-cycloaddition with singlet oxygen to afford peroxy compound $( \pm)-207$ in $69 \%$ yield. The construction of cis-decalin ( \pm )-208 from $( \pm)-207$ is finally accomplished in four steps (Scheme 49).

The first asymmetric total synthesis of eudesmadiene-12,6olide and frullanolide, two densely oxygenated members of the eudesmanolide family of sesquiterpene lactones, has been reported by Liao. ${ }^{87}$ The elaboration of the key building block 214 has been conceived by a protocol involving an anionic oxy-Cope rearrangement from bicyclo[2.2.2]octenol 213. At first, an intermolecular Diels-Alder reaction between homochiral furan 211 and masked $o$-benzoquinone (MOB) 210 prepared in situ from methoxy-phenol 209, affords tricyclic ketone 212 in $73 \%$ yield with $97 \%$ de. Then, 212 is rapidly converted into keyprecursor 213 in $65 \%$ yield over three steps. Optimization of the anionic oxy-Cope rearrangement permits to provide cis-decalin 214 in $87 \%$ yield from 213, using KHMDS and 18-crown-6 in refluxing toluene. The synthesis of target molecules has been further achieved from highly functionalized decalin $\mathbf{2 1 4}$ (Scheme 50).

Following a similar sequence, the asymmetric synthesis of the cis-decalin core $\mathbf{2 2 0}$ of the potent anticancer marine natural products superstolides A and B has been achieved by Jin. ${ }^{88}$ At first, an intermolecular $[4+2]$ cycloaddition between vinylsulfone 216 and diene 215 provides tricyclic adduct 217 with total anti/endo-facial selectivity. Vinyl acetate $\mathbf{2 1 7}$ is then converted into tertiary alcohol 218 in $41 \%$ yield over eight steps. 218 next undergoes an anionic oxy-Cope rearrangement to provide the cis-decalin 219 in $88 \%$ yield. Finally, the cis-decalin moiety 220 present in superstolides, with six stereogenic centers and a double bond has been successfully elaborated (Scheme 51).

The synthesis of aspermytin A and oblongolide $\mathrm{C}$ has been accomplished by Yoshida and Shishido employing an
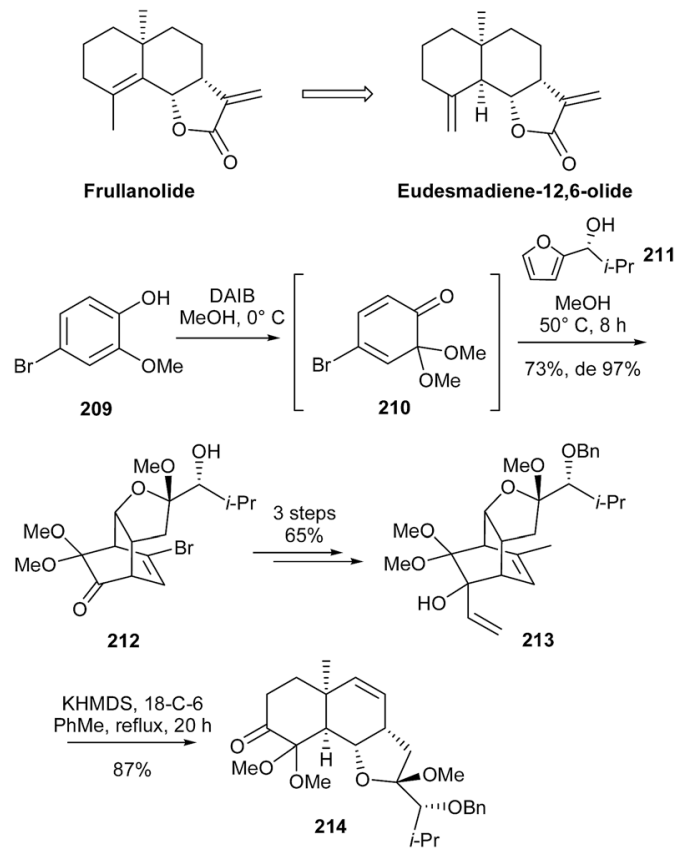

Scheme 50 Liao's total synthesis of eudesmadiene-12,6-olide and frullanolide.

intramolecular nitrile oxide-alkene [3 + 2] cycloaddition (INOC) as the key step. ${ }^{89}$ Citronellal is first transformed into nitroalkane 223 in $51 \%$ yield over eight steps, through a known kinetically controlled intramolecular ene reaction (formation of 1,2-trans-substituted product 222 from diene 221).$^{90}$ Then, upon exposure to ethylchloroformate, triethylamine and 4-DMAP, isoxazoline 224 is isolated in $81 \%$ yield with a total selectivity via
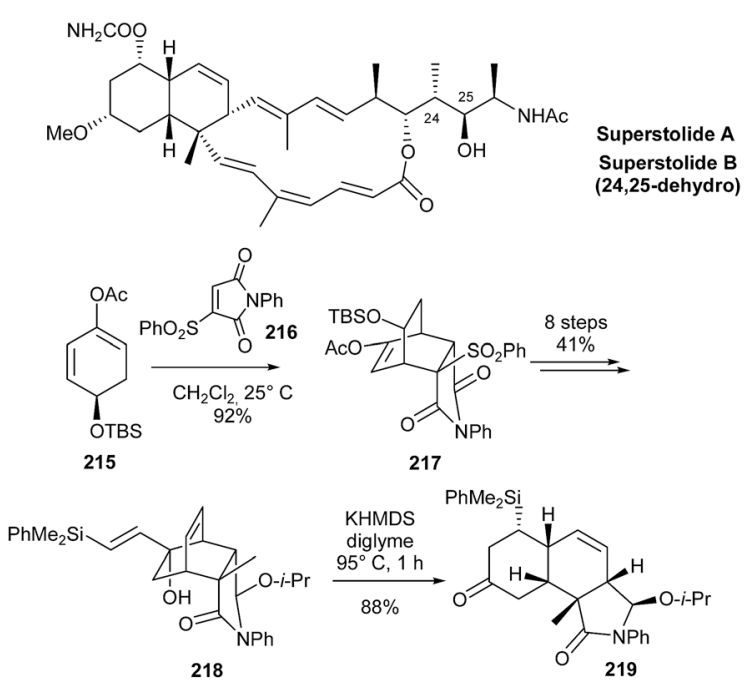

219

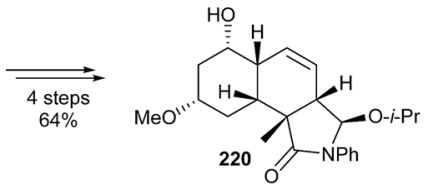

Scheme 51 Jin's synthesis of the cis-decalin core superstolides A and B. 

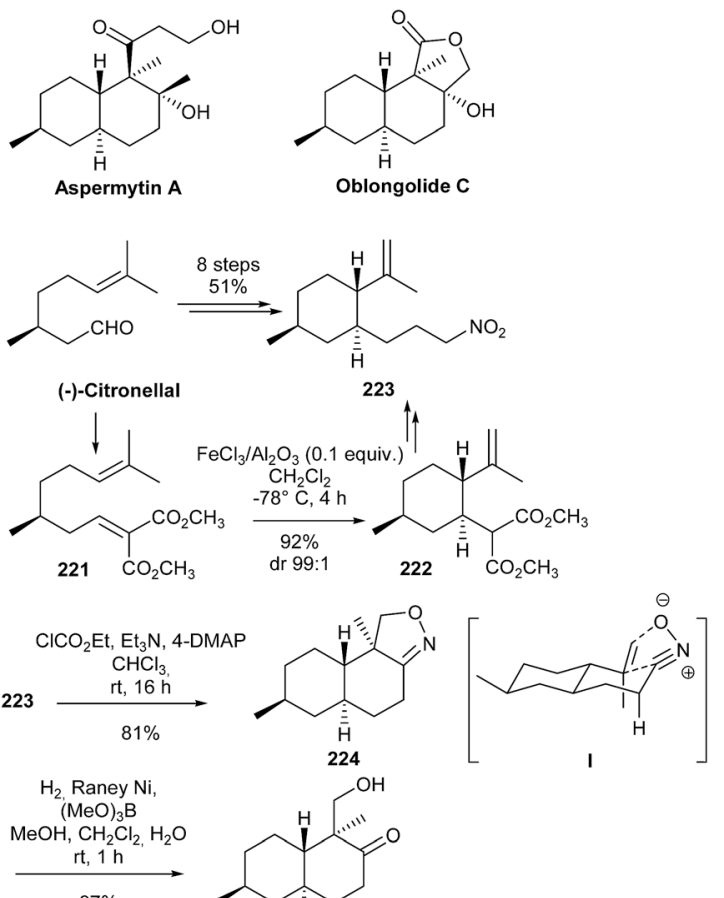
224

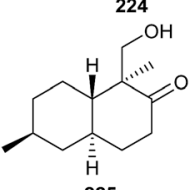

22

Scheme 52 Yoshida and Shishido synthesis of aspermytin A and oblongolide $\mathrm{C}$.

transition state I. Finally, 224 is converted into $\beta$-hydroxyketone 225, a late precursor of target molecules (Scheme 52).

Kündig has reported the first total synthesis of the sesquiterpenoid eudesmane 226, by employing an intramolecular nitrile oxide dipolar cycloaddition reaction for the construction of the cis-decalin framework. ${ }^{91}$ The synthesis begins with the transformation of (-)-cis-piperitol 227 into aldehyde 230, by means of an Ireland-Claisen rearrangement of ester 228 to give $\alpha$-alkoxy acid 229. Aldehyde 230 is then subjected to condensation with hydroxylamine hydrochloride to afford the corresponding oxime. Subsequent oxidation into the nitrile oxide in the presence of NCS/cat. pyridine is followed by a spontaneous intramolecular cycloaddition to form isoxazoline 231 in $79 \%$ yield as a single diastereomer. Finally, under hydrolytic hydrogenation conditions, 231 undergoes $\mathrm{N}-\mathrm{O}$ bond cleavage to deliver ketone 232 as an advanced intermediate of target compound 226 (Scheme 53).

\section{Ring-closing metathesis (RCM)}

The Morken's synthesis of the aglycon of the glycoterpene natural product pumilaside highlights the use of a ring-closing metathesis (RCM) strategy for the construction of the second cycle of the decalin core. ${ }^{92}$ RCM, conducted with HoveydaGrubbs second generation catalyst, furnishes bicyclic system 236 in good yield from optically active cyclohexane 235. Another notable feature of the synthesis is the access to RCM precursor 235 through a catalytic enantioselective tandem allylation strategy. In the presence of 234, 1,2-diboration of the 1,3-diene
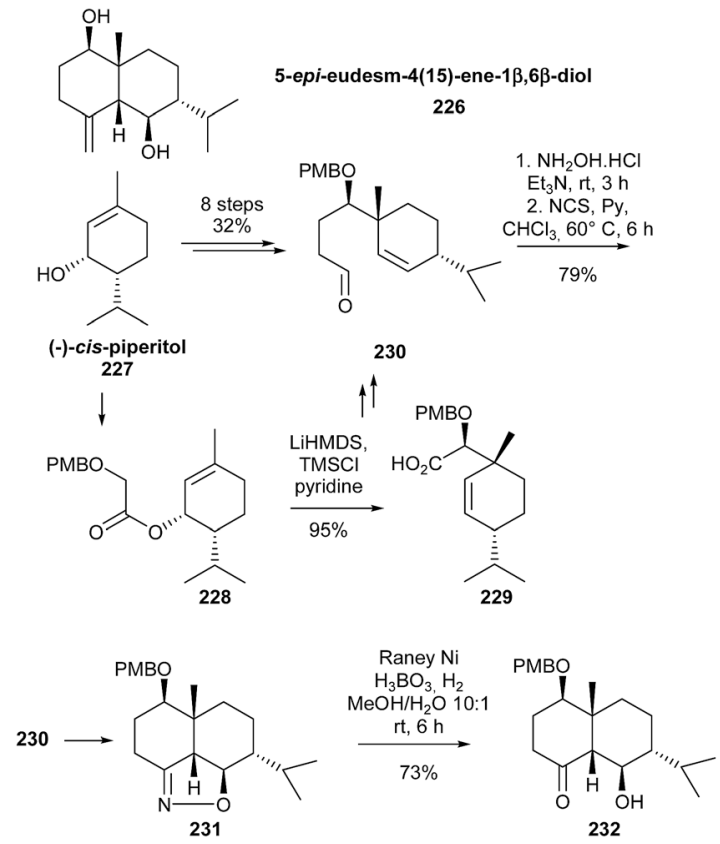

Scheme 53 Kündig's synthesis of eudesmane.

system of geranial-derivative 233, first generates an $\alpha$-chiral allylboron reagent and subsequent cascade allylboration reactions deliver trans 1,5-diol 235 in good yield and excellent stereoselection (Scheme 54).

Construction of the cis-decalin core 243 of branimycin has been accomplished by Mulzer through a key ring-closing metathesis involving cyclohexane 240, synthesized from the meso-diol 237..$^{37,93}$ The synthesis starts with the conversion of meso-237 into alkene 238 through enzymatic enantio-differentiating acetylation and functionalization. A catalytic copper mediated $\mathrm{S}_{N} 2^{\prime}$ opening of oxabicycle 238 with Grignard reagent affords the cyclohexene $\mathbf{2 3 9}$ which is then transformed into diene 240 in $42 \%$ overall yield for six steps. Ring-closing metathesis of $\mathbf{2 4 0}$ performed in the presence of 5 mol\% Grubbs second-generation catalyst allows the elaboration of the cisdecalin system, providing cis-decalin system 241 in $92 \%$ yield. Finally, reaction between ketone 241 and vinyliodide 242 leads to the target oxygen bridged product 243 (Scheme 55).
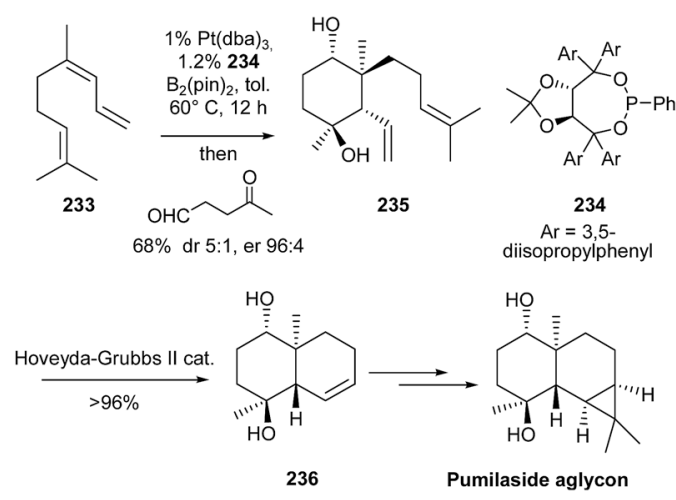

Scheme 54 Morken's synthesis of the aglycon of pumilaside. 


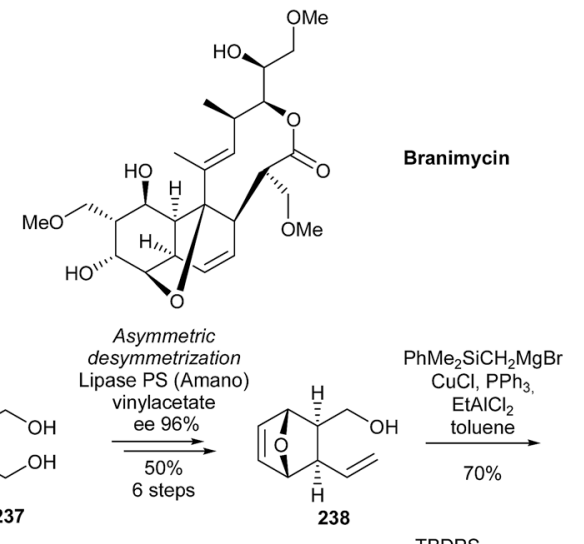

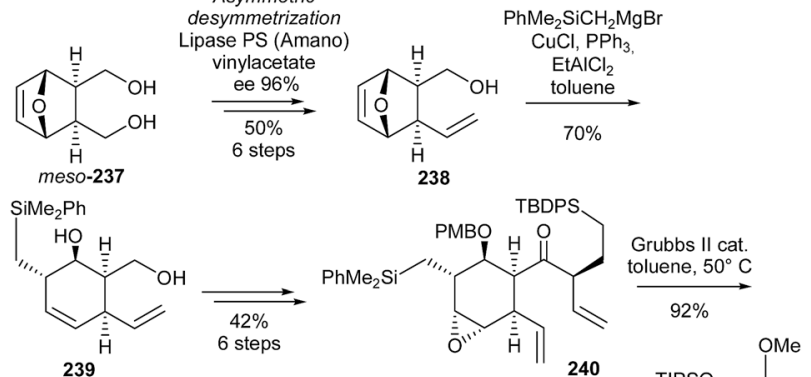

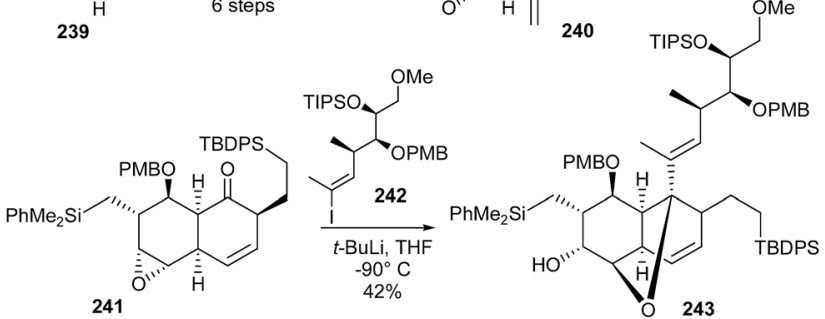

Scheme 55 Mulzer's synthesis of the cis-decalin core of branimycin.

Lee has achieved a concise synthesis of the bridged tricyclic enone core (Nicolaou's intermediate) of platencin using a ringclosing metathesis reaction for the formation of the cyclohexenone moiety. ${ }^{94}$ Meso-anhydride $\mathbf{2 4 4}$ is first desymmetrized to form the carboxylic half-ester $\mathbf{2 4 5}$ in the presence of $(\mathrm{DHQD})_{2} \mathrm{AQN}$, then diene $\mathbf{2 4 6}$ is elaborated from 245 in a 15 step sequence. The key RCM reaction, carried out with Grubbs second-generation catalyst, followed by manganese dioxide mediated oxidation delivers the desired Nicolaou's intermediate in $82 \%$ yield (Scheme 56 ).

\section{Various reactions}

\subsection{Desymmetrization of meso-decalin}

Towards the synthesis of hypoglaunine B, a complex macrodilactone sesquiterpene which possesses interesting anti-HIV

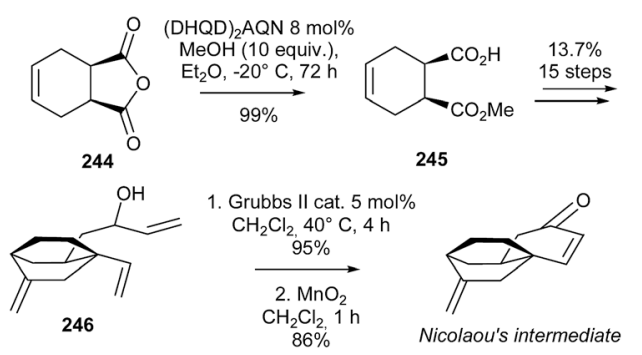

Scheme 56 Lee's synthesis of the Nicolaou's intermediate of platencin. activity, Spivey has developed a sequence where the enantiomerically enriched trans-decalin $\mathbf{2 5 1}$ is converted into furandecalin 247. ${ }^{95}$ Elaboration of key precursor 251 is based on the desymmetrization of a meso-decalin core. To this aim, epoxide 248 is first prepared in a two step sequence from naphthalene by Birch reduction and subsequent epoxidation (64\% yield over two steps). After epoxide ring opening with $\mathrm{Et}_{2} \mathrm{AlCN}$, bis-epoxide 249 is obtained through a totally diastereoselective epoxidation. trans-Diaxial ring opening of the latter (249) with $\mathrm{Me}_{3} \mathrm{Al}$, followed by selective mesylation and final anti-elimination furnishes the requisite meso diallylic tertiary alcohol $\mathbf{2 5 0}$. Epoxidative enantioselective desymmetrization of $\mathbf{2 5 0}$ is subsequently achieved in good yield $(90 \%)$ and with high $e e$ values $(92 \%)$ through a $\mathrm{Zr}$-based Sharpless asymmetric epoxidation process. Epoxide $\mathbf{2 5 1}$ is finally converted into the furandecalin 247 in a nine step sequence (Scheme 57).

\subsection{Aryne cyclization}

(+)-Tubingensin A, a carbazole-containing natural product displaying antiviral, anticancer and insecticidal natural product, has been efficiently prepared in nine steps by Garg. ${ }^{96}$ The synthetic route features a key aryne cyclization to introduce the vicinal quaternary centers. Under the reaction conditions $\left(\mathrm{NaNH}_{2}\right.$ and $\left.t-\mathrm{BuOH}\right)$, aryne cyclization of enol ether 252 delivers the desired product 253 in $84 \%$ yield. In the meantime, set up of vicinal quaternary centers is achieved with complete diastereoselectivity (Scheme 58).

\subsection{Intramolecular Heck reaction}

The synthesis of C9-oxygenated labdane diterpenoids, marrulibacetal and isopreleoheterin (with cytoprotective activities) has been reported by Nakamura from L-glutamic acid-derived lactone 254. ${ }^{97}$ Initial transformation of 254 into ester 255 is followed by Ireland-Claisen rearrangement and subsequent $O$ -

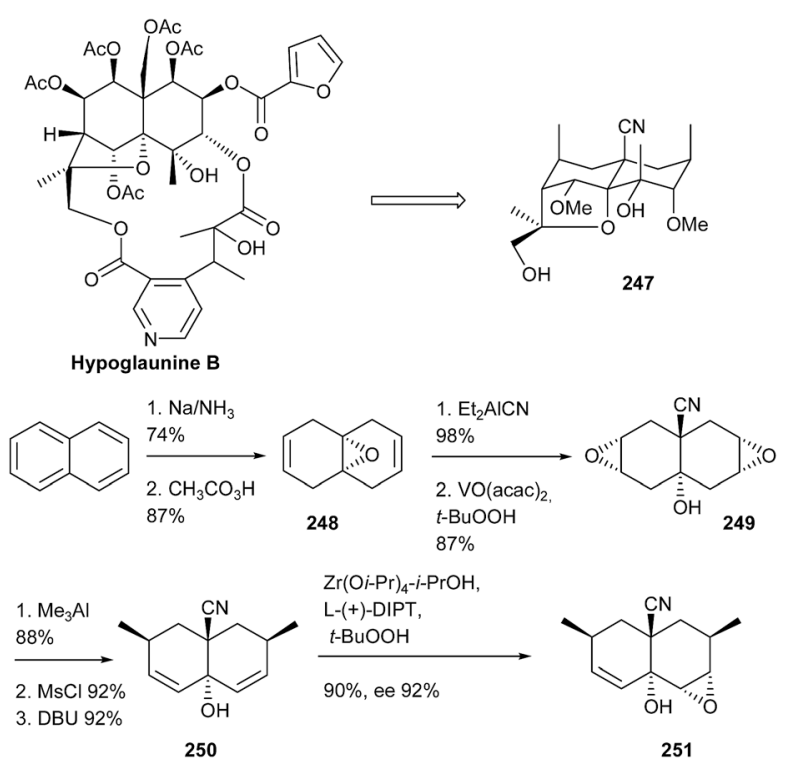

Scheme 57 Spivey's approach towards hypoglaunine B. 


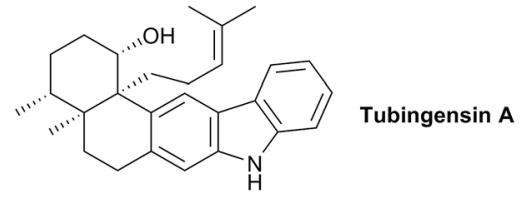

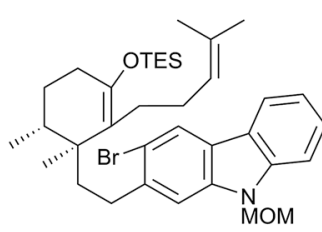

252

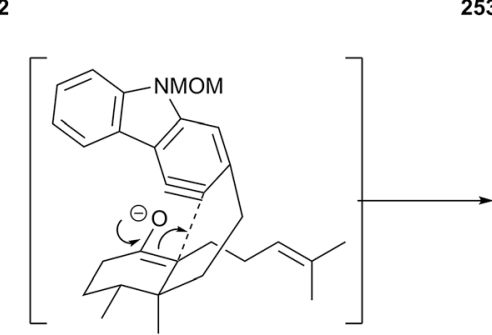

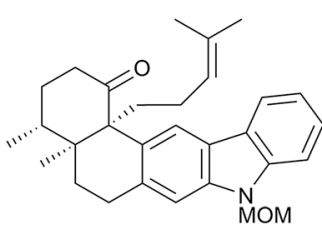

253

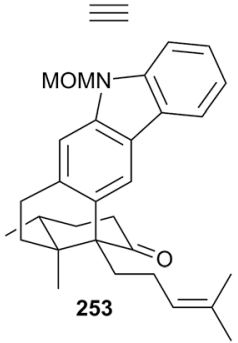

Scheme 58 Garg's total synthesis of (+)-tubingensin A.

methylation to provide tetrahydrofuran ester 256 in $94 \%$ yield and $89 \%$ de. Then, enyne 257, obtained from 256 through a base-mediated double eliminative ring-opening reaction, is converted into vinyl iodide $\mathbf{2 5 8}$. A very effective intramolecular Heck reaction allows the formation of cis-decalin 259 in $88 \%$ yield. Final olefin differentiation provides bicyclo[4.4.0]decane derivatives 260 and 261 of labdane diterpenes (Scheme 59).

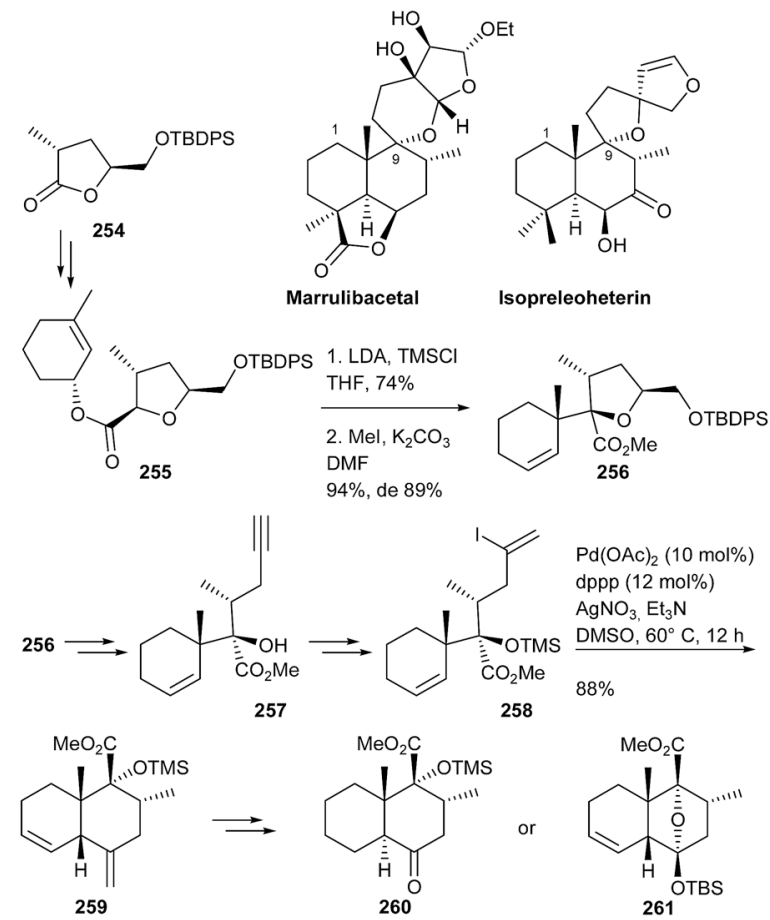

Scheme 59 Nakamura's approach towards C9-oxygenated labdane diterpenoids.

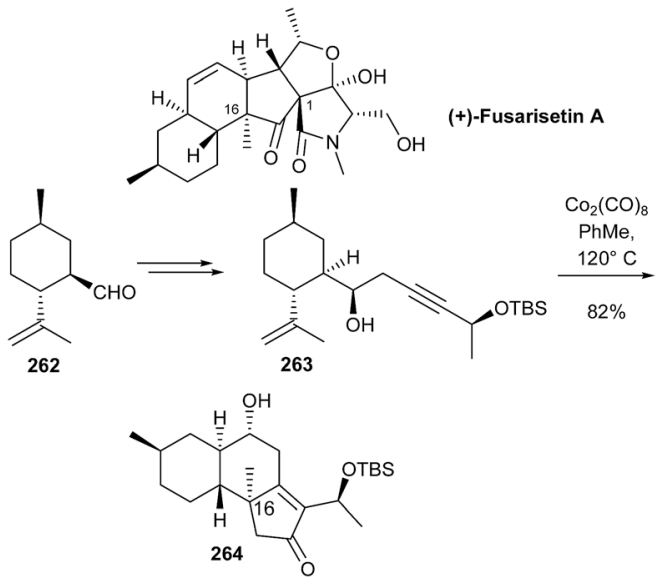

Scheme $60 \mathrm{Li}$ and Yang total synthesis of (+)-fusarisetin A.

\subsection{Intramolecular Pauson-Khand reaction}

An asymmetric total synthesis of ( + )-fusarisetin A, an emerging anticancer agent, has recently been performed by Li and Yang in 16 steps..$^{98}$ The strategy, which features the stereoselective construction of the trans-decalin subunit 264 by intramolecular Pauson-Khand reaction, offers an efficient alternative to the previously used IMDA route. The synthesis starts with the straightforward elaboration of enyne 263 from commercially available aldehyde 262. After optimization, the $\mathrm{Co}_{2}(\mathrm{CO})_{8}$-mediated intramolecular Pauson-Khand reaction, conducted at 120 ${ }^{\circ} \mathrm{C}$ in toluene as solvent, allows for the stereoselective construction of the cyclopentenone $\mathbf{2 6 4}$ with a unique quaternary chiral center at C16. This tricyclic product 264 is further converted into the target molecule (Scheme 60).

\section{Conclusions}

This review summarizes recent examples of naturally occurring complex decalin systems construction. With regards to the number of methods that have been developed for their preparation, the importance of natural products containing highly functionalized and substituted decalin motifs is clearly evidenced. As highlighted in the selection of examples presented above, notable accomplishments in the field are still achieved by means of conventional (venerable) methodologies, meaning that they continue to thrive and to stimulate the imagination of synthetic chemists engaged in the assembly of complex decalins. However, concomitant emergence of new processes and sequences has provided rich opportunities for the rapid and selective generation of molecular diversity and complexity in decalin systems. Therefore, with such myriad and diverse methods, construction of complex decalins can now be planned at different stages of the synthetic route, in a tandem or sequential process, with high efficacy and stereoselectivity.

\section{Notes and references}

1 G. Li, S. Kusari and M. Spiteller, Nat. Prod. Rep., 2014, 31, 1175. 
2 H. Akita, Heterocycles, 2013, 87, 1625.

3 M. Saleem, H. Hussain, I. Ahmed, T. van Reec and K. Krohn, Nat. Prod. Rep., 2011, 28, 1534.

4 M. A. Varner and R. B. Grossman, Tetrahedron, 1999, 55, 13867.

5 V. Singh, S. R. Iyer and S. Pal, Tetrahedron, 2005, 35, 9197.

6 T. Tokoroyama, Synthesis, 2000, 611.

7 O. Diels and K. Alder, Liebigs Ann. Chem., 1928, 460.

8 P. T. Parvatkar, H. K. Kadam and S. G. Tilve, Tetrahedron, 2014, 70, 2857.

9 C. C. Nawrat and C. J. Moody, Angew. Chem., Int. Ed., 2014, 53, 2056.

10 X. Jiang and R. Wang, Chem. Rev., 2013, 113, 5515.

11 G. Deslongchamps and P. Deslongchamps, Tetrahedron, 2013, 69, 6022.

12 J.-A. Funel and S. Abele, Angew. Chem., Int. Ed., 2013, 52, 3822.

13 H. Pellissier, Tetrahedron, 2012, 68, 2197.

14 J.-L. Li, T.-Y. Liu and Y.-C. Chen, Acc. Chem. Res., 2012, 45, 1491.

15 L. Bernardi, M. Fochi, M. C. Franchini and A. Ricci, Org. Biomol. Chem., 2012, 10, 2911.

16 M. Juhl and D. Tanner, Chem. Soc. Rev., 2009, 38, 2983.

17 E. M. Stocking and R. M. Williams, Angew. Chem., Int. Ed., 2003, 42, 3078.

18 K. C. Nicolaou, S. A. Snyder, T. Montagnon and G. Vassilikogiannakis, Angew. Chem., Int. Ed., 2002, 41, 1668.

19 B. R. Bear, S. M. Sparks and K. J. Shea, Angew. Chem., Int. Ed., 2001, 40, 820.

20 G. Majetich, Y. Zhang, X. Tian, J. E. Britton, Y. Li and R. Phillips, Tetrahedron, 2011, 67, 10129.

21 F. Portalier, F. Bourdreux, J. Marrot, X. Moreau, V. Coeffard and C. Greck, Org. Lett., 2013, 15, 5642.

22 D. Y.-K. Chen, Synlett, 2011, 2459.

23 L. Zhu, C. Zhou, W. Yang, S. He, G.-J. Cheng, X. Zhang and C.-S. Lee, J. Org. Chem., 2013, 78, 7912.

24 K. C. Nicolaou, G. S. Tria and D. J. Edmonds, Angew. Chem., Int. Ed., 2008, 47, 1780.

25 Y. Zou, C.-H. Chen, C. D. Taylor, B. M. Foxman and B. B. Snider, Org. Lett., 2007, 9, 1825.

26 K. Tiefenbacher and J. Mulzer, J. Org. Chem., 2009, 74, 2937. 27 M. E. Jung and D. Yoo, Org. Lett., 2011, 13, 2698.

28 M. E. Jung and M. Guzaev, J. Org. Chem., 2013, 78, 7518.

29 H. Hopf and M. S. Sherburn, Angew. Chem., Int. Ed., 2012, 51, 2298.

30 S. V. Pronin and R. A. Shenvi, J. Am. Chem. Soc., 2012, 134, 19604.

31 H. Miyaoka, Y. Abe, N. Sekiya, H. Mitome and E. Kawashima, Chem. Commun., 2012, 48, 901.

32 D. A. Evans, D. J. Adams and E. E. Kwan, J. Am. Chem. Soc., 2012, 134, 8162.

33 S. Mondal, R. N. Yadav and S. Ghosh, Org. Lett., 2011, 13, 6078.

34 F. Löbermann, L. Weisheit and D. Trauner, Org. Lett., 2013, 15, 4324 .

35 B. M. Trost, E. J. McEachern and F. D. Toste, J. Am. Chem. Soc., 1998, 120, 12702.
36 C. Wang, L. Kong, Y. Li and Y. Li, Eur. J. Org. Chem., 2014, 3556.

37 V. S. Enev, W. Felzmann, A. Gromov, S. Marchart and J. Mulzer, Chem.-Eur. J., 2012, 18, 9651.

38 (a) G. Stork and A. W. Burgstahler, J. Am. Chem. Soc., 1955, 77, 5068; (b) A. Eschenmoser, L. Ruzicka, O. Jeger and D. Arigoni, Helv. Chim. Acta, 1955, 38, 1890; (c) A. Eschenmoser and D. Arigoni, Helv. Chim. Acta, 2005, 88, 3011.

39 R. J. Felix, C. Munro-Leighton and M. R. Gagné, Acc. Chem. Res., 2014, 47, 2319.

40 S. Goncalves, S. Santoro, M. Nicolas, A. Wagner, P. Maillos, F. Himo and R. Baati, J. Org. Chem., 2011, 76, 3274.

41 D. Yang, X. Ye and X. Ming, J. Org. Chem., 2000, 65, 2208.

42 K. Surendra, G. Rajendar and E. J. Corey, J. Am. Chem. Soc., 2014, 136, 642.

43 K. Surendra and E. J. Corey, J. Am. Chem. Soc., 2012, 134, 11992.

44 S. Desjardins, J.-C. Andrez and S. Canesi, Org. Lett., 2011, 13, 3406.

45 S. A. Snyder, D. S. Treitler and A. Schall, Tetrahedron, 2010, 66, 4796.

46 M. J. Geier and M. R. Gagné, J. Am. Chem. Soc., 2014, 136, 3032.

47 J. G. Sokol, C. S. Korapala, P. S. White, J. J. Becker and M. R. Gagné, Angew. Chem., Int. Ed., 2011, 50, 5658.

48 S. G. Sethofer, T. Mayer and F. D. Toste, J. Am. Chem. Soc., 2010, 132, 8276.

49 B. M. Trost, A. C. Gutierrez and E. M. Ferreira, J. Am. Chem. Soc., 2010, 132, 9206.

50 J. Huang, D. Foyle, X. Lin and J. Yang, J. Org. Chem., 2013, 78, 9166.

51 M. Uosis-Martin, G. Dan Pantoş, M. F. Mahon and S. E. Lewis, J. Org. Chem., 2013, 78, 6253.

52 M. Uosis-Martin, M. F. Mahon, M. Yevglevskis and S. E. Lewis, Synlett, 2011, 2211.

53 C. L. Lyall, M. Uosis-Martin, J. P. Lowe, M. F. Mahon, G. Dan Pantoş and S. E. Lewis, Org. Biomol. Chem., 2013, 11, 1468.

54 G. Baddeley and E. Wrench, J. Chem. Soc., 1959, 1324.

55 L. Zhu, J. Luo and R. Hong, Org. Lett., 2014, 16, 2162.

56 M. E. Jung and M. Guzaev, J. Org. Chem., 2013, 78, 7518.

57 P. Buchschacher, A. Fürst and J. Gutzwiller, Org. Synth., 1990, 7, 368.

58 B. Schmalzbauer, J. Herrmann, R. Müller and D. Mensche, Org. Lett., 2013, 15, 964.

59 H. Hagiwara and H. Uda, J. Org. Chem., 1988, 53, 2308.

60 B. Bradshaw, G. Etxebarria-Jardi and J. Bonjoch, J. Am. Chem. Soc., 2010, 132, 5966.

61 J. S. Yadav, R. Goreti, S. Pabbaraja and B. Sridhar, Org. Lett., 2013, 15, 3782.

62 K. C. Nicolaou, L. Shi, M. Lu, M. R. Pattanayak, A. A. Shah, H. A. Ioannidou and M. Lamani, Angew. Chem., Int. Ed., 2014, 53, 10970.

63 S. Anwar, H.-J. Chang and K. Chen, Org. Lett., 2011, 13, 2200.

64 N. T. Vo, R. D. M. Pace, F. O'Hara and M. J. Gaunt, J. Am. Chem. Soc., 2008, 130, 404.

65 P. C. Roosen and C. D. Vanderwal, Org. Lett., 2014, 16, 4368. 
66 C. S. S. Rao, G. Kumar, K. Rajagopalan and S. Swaminathan, Tetrahedron, 1982, 38, 2195.

67 J. R. Scheerer, J. F. Lawrence, G. C. Wang and D. A. Evans, J. Am. Chem. Soc., 2007, 129, 8968.

68 H. Xue, J. Yang and P. Gopal, Org. Lett., 2011, 13, 5696.

69 For a recent systematic investigation of the transannular Michael cascade, see: H. Xue, P. Gopal and J. Yang, J. Org. Chem., 2012, 77, 8933.

70 K. C. Nicolaou, G. Scott Tria, D. J. Edmonds and M. Kar, J. Am. Chem. Soc., 2009, 131, 15909.

71 O. V. Barykina, K. L. Rossi, M. J. Rybak and B. B. Snider, Org. Lett., 2009, 11, 5334.

72 K. Palanichamy, A. V. Subrahmanyam and K. P. Kaliappan, Org. Biomol. Chem., 2011, 9, 7877.

73 L. Zhou, Y. Yao, W. Xu and G. Liang, J. Org. Chem., 2014, 79, 5345.

74 A. R. Burns, J. S. Gonzalez and H. W. Lam, Angew. Chem., Int. Ed., 2012, 51, 10827.

75 R. H. Munday, R. M. Denton and J. C. Anderson, J. Org. Chem., 2008, 73, 8033.

76 K. Ravindar, P.-Y. Caron and P. Deslongchamps, J. Org. Chem., 2014, 7979.

77 K. Ravindar, P.-Y. Caron and P. Deslongchamps, Org. Lett., 2013, 15, 6270.

78 T. Tricotet and R. Brückner, Eur. J. Org. Chem., 2007, 1069.

79 S. Breitler and E. M. Carreira, Angew. Chem., Int. Ed., 2013, 52, 11168.

80 T. Yoshimitsu, S. Nojima, M. Hashimoto and T. Tanaka, Org. Lett., 2011, 13, 3698.

81 A. Fernàndez-Mateos, S. Encinas Madrazo, P. Herrero Teijon, R. Rabanedo Clemente, R. Rubio Gonzàlez and F. Sanz Gonzàlez, J. Org. Chem., 2013, 78, 9571.

82 S. P. Morcillo, D. Miguel, S. Resa, A. Martín-Lasanta, A. Millan, D. Choquesillo-Lazarte, J. M. García-Ruiz, A. J. Mota, J. Justicia and J. M. Cuerva, J. Am. Chem. Soc., 2014, 136, 6943.
83 J. C. Lo, Y. Yabe and P. S. Baran, J. Am. Chem. Soc., 2014, 136, 1304.

84 B.-C. Hong, C.-W. Lin, W.-K. Liao and G.-H. Lee, Org. Lett., 2013, 15, 6258.

85 X. Liu and C.-S. Lee, Org. Lett., 2012, 14, 2886.

86 P. Malek Mirzayans, R. H. Pouwer, C. M. Williams and

P. V. Bernhardt, Eur. J. Org. Chem., 2012, 1633.

87 Y.-Y. Chou and C.-C. Liao, Org. Lett., 2013, 15, 1584.

88 L. Chen, Z. Hua, G. Li and Z. Jin, Org. Lett., 2011, 13, 3580.

89 A. Inoue, M. Kanematsu, S. Mori, M. Yoshida and K. Shishido, Synlett, 2013, 0061.

90 (a) L. F. Tietze, U. Beifuss, J. Antel and G. M. Sheldrick, Angew. Chem., Int. Ed. Engl., 1988, 27, 703; (b) L. F. Tietze and U. Beifuss, Synthesis, 1988, 359; (c) L. F. Tietze and U. Beifuss, Org. Synth., 1993, 71, 167.

91 G. Parthasarathy, C. Besnard and E. P. Kündig, Chem. Commun., 2012, 48, 11241.

92 G. E. Ferris, K. Hong, I. A. Roundtree and J. P. Morken, J. Am. Chem. Soc., 2013, 135, 2501.

93 V. S. Enev, M. Drescher and J. Mulzer, Org. Lett., 2008, 10, 413.

94 S. Y. Yun, J.-C. Zheng and D. Lee, Angew. Chem., Int. Ed., 2008, 47, 6201.

95 (a) M. J. Webber, S. A. Warren, D. M. Grainger, M. Weston, S. Clark, S. J. Woodhead, L. Powell, S. Stokes, A. Alanine, J. P. Stonehouse, C. S. Frampton, A. J. P. White and A. C. Spivey, Org. Biomol. Chem., 2013, 11, 2514; (b) A. C. Spivey, S. J. Woodhead, M. Weston and B. I. Andrews, Angew. Chem., Int. Ed., 2001, 40, 769.

96 S. A. E. Goetz, A. L. Silberstein, M. A. Corsello and N. K. Garg, J. Am. Chem. Soc., 2014, 136, 3036.

97 Y. Akahori, H. Yamakoshi, Y. Sawayama, S. Hashimoto and S. Nakamura, J. Org. Chem., 2014, 79, 720.

98 J. Huang, L. Fang, R. Long, L.-L. Shi, H.-J. Shen, C.-C. Li and Z. Yang, Org. Lett., 2013, 15, 4018. 